\title{
A New Geometry Definition and Generation Method For a Face Gear Meshed With a Spur Pinion
}

\section{Xianlong Peng ( $\nabla$ pxljsh@xust.edu.cn )}

Northwestern Polytechnical University

Original Article

Keywords: Face gear, Geometry definition, Manufacturing, Surface deviation, Meshing performance

Posted Date: January 13th, 2021

DOI: https://doi.org/10.21203/rs.3.rs-143568/v1

License: (9) This work is licensed under a Creative Commons Attribution 4.0 International License. Read Full License

Version of Record: A version of this preprint was published at Proceedings of the Institution of Mechanical Engineers, Part B: Journal of Engineering Manufacture on December 6th, 2021. See the published version at https://doi.org/10.1177/09544054211060927. 


\section{Title page}

A new geometry definition and generation method for a face gear meshed with a spur pinion

Xian-Long Peng, born in 1982, is currently an associate professor at Xi' an University of Science and Technology, China. He received his $\mathrm{PhD}$ degree from Northwestern Polytechnical University, China, in 2013. His research interests include gear transmission design and manufacturing.

Tel: +86-181-92270760; E-mail: pxljsh@xust.edu.cn

Corresponding author: Xian-Long Peng E-mail: pxljsh@xust.edu.cn 


\title{
A new geometry definition and generation method for a face gear meshed with a spur pinion
}

\author{
Xian-Long Peng ${ }^{1}$
}

Received June xx, 201x; revised February xx, 201x; accepted March xx, 201x

(C) Chinese Mechanical Engineering Society and Springer-Verlag Berlin Heidelberg 2017

\begin{abstract}
The conventional tooth surface of a face gear is difficult to manufacture, and the cutter is not uniform even though the parameters of its mating pinion slightly change. Based on the analysis of the features of the tooth surface, a new developable ruled surface approach is proposed that defines the tooth flank of the face gear, for which the most important feature is that it could be generated by a straight-edged cutter. This study presents mathematical models of the cutter and the new tooth surface and the corresponding deviation, correction and generation method for this surface, which are investigated through numerical examples. The manufacturing process is simulated by VERICUT software, and the results demonstrate that even when the principle deviation is added to the machined deviation, the absolute deviation is on the microscale. The meshing and contact simulation shows that the new surface could obtain good meshing performance when the number of face gear teeth is greater than three times the number of pinion teeth. This research provides a new method for manufacturing face gears.
\end{abstract}

Keywords: Face gear - Geometry definition - Manufacturing • Surface deviation $\bullet$ Meshing performance

\section{Introduction}

Face gear drives are an important form of angular transmission because these devices have some special advantages [1-2]; however, face gear drives are not used in a sufficiently wide range of applications. One of the primary reasons for this lack of usage is the low processing efficiency of these devices, which limits large-scale production and leads to high application costs. Moreover,

Xian-Long Peng

pxljsh@xust.edu.cn

1 College of Mechanical Engineering, Xi' an University of Science and Technology, Xi' an 710054, China the surface profile of a face gear tooth is regarded as a unique complex space. A face gear tooth is considered an undevelopable ruled surface according to the theory proposed by Litvin [1-3], which limits the development of new face gear generation methods. However, most manufacturing methods for face gears currently depend on this theory [4-10].

The surface of a face gear tooth is defined by it mates with a spur pinion. Hence, the simplest method for machining a face gear is the application of a shaping device that is identical to the pinion [1-4]. However, this method can only be used for soft or low-precision tooth surfaces. The tools used to generate face gears containing hard or high-precision tooth surfaces are worm cutters or grinders [10] and disk cutters or grinders [5-9], which both duplicate the involute of the pinion. Although the indexing motion of the worm cutters/grinders is continuous, the generated surfaces are in point contact, the tool needs transverse motion in the longitudinal direction to process the whole tooth surface, and the processing efficiency is not very high. The processing efficiency of disk cutters/grinders is much lower than that of the worm cutters/grinders because of the single-tooth indexing and transverse motion. Furthermore, it is impossible to standardize the worm or disk tools through involute duplication [11]. To standardize the cutter and increase the processing efficiency, Stadtfeld proposed the use of a Coniflex cutter for bevel gear machining, in which they modified the cutter rotation to make the plane of the cutter simulate the involute of the pinion [11-12]. In theory, the plane of the cutter should be in point contact with the face gear tooth surface; however, in practice, the generated tooth surface is constrained in line contact with the plane, which results in a large or macroscopic deviation between 
the generated and theoretical surfaces [13]. Tang et al. proposed milling and planing methods for face gear generation using simple tools [14-15]. Although the accuracy of the tooth surface was guaranteed, all of these methods are profiling approaches, and the surfaces of the workpiece and cutter are in point contact. Kubo claimed that gear geometry should be regarded as a function of the production method, and an example of an invo-planar bevel gear demonstrated that the cutting time was greatly reduced and a smoother tooth flank was obtained [16]. From these results and considering the manufacturing difficulty of the conventional tooth surface of the face gear, the geometry of the face gear may need to be changed.

Based on a conventional face gear, the surface features of the face gear tooth are analyzed, introducing a new geometry definition in which the tooth surface of the face gear could be represented by a developable ruled surface. A method is also applied to correct the surface to increase precision. If these corrections are neglected, the tooth surface must be modified to improve the unloaded meshing performance. A method using a 5-axis planer for face gear manufacturing is proposed, which enables the generation of face gear tooth surfaces with a straight-edged cutter. Mathematical models for the cutter and numerical control (NC) motion are established. The results in this study indicate good meshing performance and high cutting precision, which are simulated by tooth contact analysis (TCA) and VERICUT (NC verification software), respectively.

\section{New Geometry Definition for a Face Gear}

\subsection{Conventional Geometry}

Fig. 1 shows a face gear meshed with a spur pinion $(i=1)$ or a shaper $(i=\mathrm{s})$. Litvin elaborated the generation of the tooth surface of a face gear in detail [1-2]; herein, this information is briefly introduced to lay the foundation for this paper. It is assumed that the position and unit normal vectors of the involute surface $\Sigma_{i}$ of the pinion and shaper are represented by $\boldsymbol{R}_{i}\left(\theta_{i}, u_{i}\right)$ and $\boldsymbol{n}_{i}\left(\theta_{i}, u_{i}\right)$, respectively. Note that $\left(\theta_{i}, u_{i}\right)$ are the Gaussian coordinates of $\Sigma_{i}$ measured in the profile and longitudinal directions, wherein the fourth element of $\boldsymbol{n}_{i}$ is 0 . The tooth surface $\Sigma_{2}$ of the face gear is the envelope of the surface $\Sigma_{\mathrm{s}}$ of the shaper. Hence, the position and normal vectors of $\Sigma_{2}$ can be expressed as follows:

$$
\boldsymbol{R}_{2}\left(\theta_{\mathrm{s}}, u_{\mathrm{s}}, \varphi_{\mathrm{s}}\right)=\boldsymbol{M}_{2 \mathrm{~s}}\left(\varphi_{2}, \varphi_{\mathrm{s}}\right) \boldsymbol{R}_{\mathrm{s}}\left(\theta_{\mathrm{s}}, u_{\mathrm{s}}\right)
$$

$$
\boldsymbol{n}_{2}\left(\theta_{\mathrm{s}}, u_{\mathrm{s}}, \varphi_{\mathrm{s}}\right)=\boldsymbol{M}_{2 \mathrm{~s}}\left(\varphi_{2}, \varphi_{\mathrm{s}}\right) \boldsymbol{n}_{\mathrm{s}}\left(\theta_{\mathrm{s}}, u_{\mathrm{s}}\right)
$$

where $\boldsymbol{M}_{2 \mathrm{~s}}$ represents the coordinate transformation from $S_{\mathrm{s}}$ to $S_{2}$. These Cartesian right-hand coordinate systems are shown in Fig. 1. Note that $\varphi_{\mathrm{s}}$ and $\varphi_{2}$ are the rotational angles of the shaper around $z_{\mathrm{s}}$ and the face gear around $z_{2}$, respectively, which satisfy the gear ratio and could be related to $\left(\theta_{i}, u_{i}\right)$ by a meshing equation:

$$
\begin{gathered}
\varphi_{2}=\varphi_{\mathrm{s}} N_{\mathrm{s}} / N_{2} \\
f_{2 \mathrm{~s}}\left(\theta_{\mathrm{s}}, u_{\mathrm{s}}, \varphi_{\mathrm{s}}\right)=\boldsymbol{n}_{2} \cdot \partial \boldsymbol{R}_{2} / \partial \varphi_{\mathrm{s}}=0
\end{gathered}
$$

where $N_{\mathrm{s}}$ and $N_{2}$ are the numbers of teeth in the shaper and face gear, respectively. The parameters in Fig. 1 are the shaft angle $\gamma$ between $z_{i}$ and $z_{2}$, the inner radius $L_{1}$ constrained by undercutting, the outer radius $L_{2}$ constrained by pointing, and the axode cone angles $\gamma_{i}$ and $\gamma_{2}$ measured from the instantaneous axis $O_{2} P$ to axes $z_{i}$ and $z_{2}$, wherein radius $r_{\mathrm{p} i}$ of pitch circle of gear $i$.

Eqs. (1)-(4) and Fig. 1 completely describe tooth surface $\Sigma_{2}$, which could be used in numerical calculations, gear modeling and surface feature analysis.

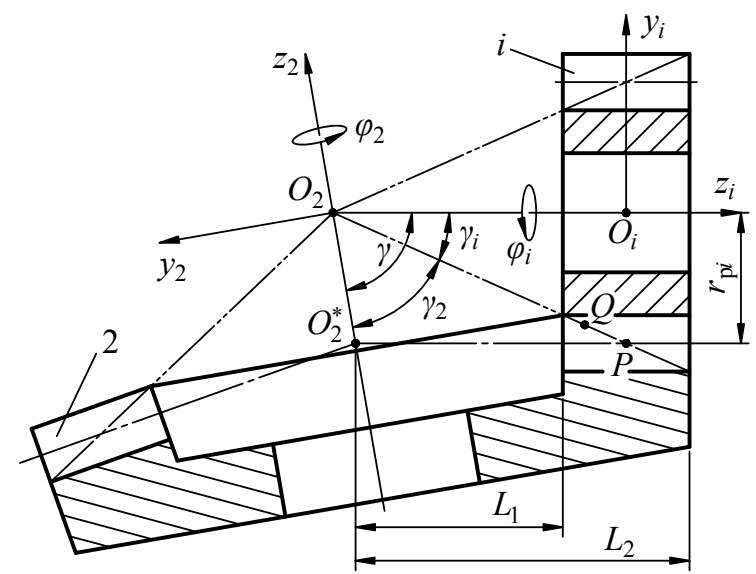

Figure 1 Face gear meshed with a pinion $(i=1)$ or a shaper $(i=\mathrm{s})$

\subsection{A Special Contact Line}

Fig. 2 shows a special contact line $L_{2 \mathrm{~s}}$ when surface $\Sigma_{2}$ is meshed with $\Sigma_{\mathrm{s}}$ at rotation angles $\varphi_{\mathrm{s}}$ and $\varphi_{2}$ of 0 , in which $L_{2 \mathrm{~s}}$ extends from the top of the toe to the root of the heel. A view of the end face reveals that $L_{2 \mathrm{~s}}$ is an involute with the same profile as the shaper because the line lies in surface $\Sigma_{\mathrm{s}}$. Any point on $L_{2 \mathrm{~s}}$ is tangent to the involute marked by inv in surface $\Sigma_{\mathrm{s}}$ and the straight line marked by $s l$ in 
surface $\Sigma_{2} . L_{2 \mathrm{~s}}$ is also tangent to the profile line $g l$, which is usually used in the drawing surface $\Sigma_{2}$, the angle from this line to axis $y_{2}$ is equal to $\gamma$. Moreover, an angle, which is referred to as the differential angle in Section 2.5, exists between lines $s l$ and $g l$ (an enlarged view of this angle is shown in Fig. 2).

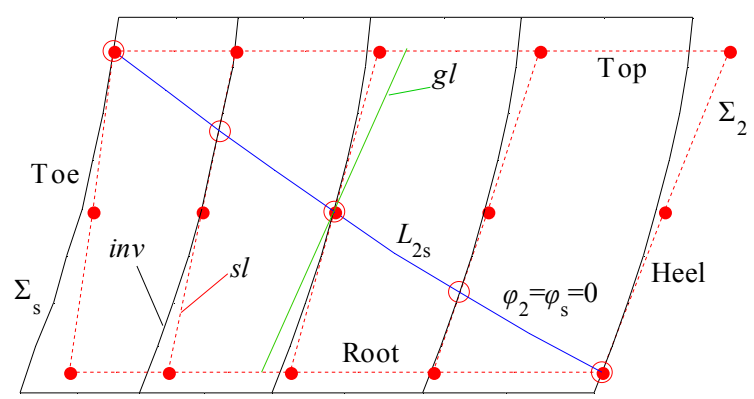

Figure 2 A Special Contact Line in Surfaces $\Sigma_{\mathrm{s}}$ and $\Sigma_{2}$

The most important phenomenon shown in Fig. 2 is that $L_{2 \mathrm{~s}}$ is an involute extending in the longitudinal direction of the face gear tooth that is tangent to the involute inv in $\Sigma_{\mathrm{s}}$ and the straight line $s l$ in $\Sigma_{2}$ at a point where the three lines have the same normal. Hence, based on this phenomenon, from the aspect of simplifying face gear manufacturing, researchers must determine if surface $\Sigma_{2}$ could be regarded as a family of straight lines that are tangent either to $L_{2 \mathrm{~s}}$ at different cross sections or to the end face involute at different points that are arranged in the longitudinal direction of the face gear tooth and change with respect to the pressure angle. If this conclusion is true, which means that the tooth surface of the face gear can be generated by a straight-edged cutter, the surfaces of the face gear tooth and cutter will be in line contact, which means a high cutting efficiency.

\subsection{Straight Line Deviation}

The straight line $s l$ deviates from surface $\Sigma_{2}$, and it is valuable to consider the range of this deviation to determine whether the deviation could be ignored.

We try to assess this deviation through a numerical method. As the direction of the straight line is unknown, three points in surface $\Sigma_{2}$ are used to determine the straight line and automatically find its direction. Then, the deviation is calculated, and the corresponding steps are elucidated hereafter:

(1) A point in surface $\Sigma_{2}$ with a pitch cone $O_{2}^{*} P$ can be represented as follows:

$$
\left\{\begin{array}{l}
R_{2 z}\left(\theta_{\mathrm{s}}, u_{\mathrm{s}}, \varphi_{\mathrm{s}}\right)=-L \cos \gamma-r_{\mathrm{ps}} / \sin \gamma \\
\sqrt{R_{2 x}^{2}\left(\theta_{\mathrm{s}}, u_{\mathrm{s}}, \varphi_{\mathrm{s}}\right)+R_{2 y}^{2}\left(\theta_{\mathrm{s}}, u_{\mathrm{s}}, \varphi_{\mathrm{s}}\right)}=L \sin \gamma \\
f_{2 \mathrm{~s}}\left(\theta_{\mathrm{s}}, u_{\mathrm{s}}, \varphi_{\mathrm{s}}\right)=0
\end{array}\right.
$$

where $R_{2 i}(i=x, y, z)$ is the component of vector $\boldsymbol{R}_{2}$ on axis $i 2$ and $L$ is a given discrete value representing the radius of the point. The position vector of points determined from Eq. (5) is denoted $\boldsymbol{R}_{2}^{*}$.

(2) Another tooth surface $\Sigma_{2}^{\#}$ is introduced that is the same as $\Sigma_{2}$, and the corresponding position vector, surface parameters and meshing equation are marked with a superscript \#. Accordingly, the equation of the straight line in $\Sigma_{2}$ could be expressed as follows:

$$
\left\{\begin{array}{l}
R_{2 z}\left(\theta_{\mathrm{s}}, u_{\mathrm{s}}, \varphi_{\mathrm{s}}\right)=-L \cos \gamma-\left(r_{\mathrm{ps}}-m\right) / \sin \gamma \\
f_{2 \mathrm{~s}}\left(\theta_{\mathrm{s}}, u_{\mathrm{s}}, \varphi_{\mathrm{s}}\right)=0 \\
R_{2 \mathrm{z}}^{\#}\left(\theta_{\mathrm{s}}^{\#}, u_{\mathrm{s}}^{\#}, \varphi_{\mathrm{s}}^{\#}\right)=-L \cos \gamma-\left(r_{\mathrm{ps}}+m\right) / \sin \gamma \\
f_{2 \mathrm{~s}}^{\#}\left(\theta_{\mathrm{s}}^{\#}, u_{\mathrm{s}}^{\#}, \varphi_{\mathrm{s}}^{\#}\right)=0 \\
\frac{R_{2 x}\left(\theta_{\mathrm{s}}, u_{\mathrm{s}}, \varphi_{\mathrm{s}}\right)-R_{2 x}^{*}}{R_{2 x}^{\#}\left(\theta_{\mathrm{s}}^{\#}, u_{\mathrm{s}}^{\#}, \varphi_{\mathrm{s}}^{\#}\right)-R_{2 x}^{*}}=\frac{R_{2 y}\left(\theta_{\mathrm{s}}, u_{\mathrm{s}}, \varphi_{\mathrm{s}}\right)-R_{2 y}^{*}}{R_{2 y}^{\#}\left(\theta_{\mathrm{s}}^{\#}, u_{\mathrm{s}}^{\#}, \varphi_{\mathrm{s}}^{\#}\right)-R_{2 y}^{*}} \\
\frac{R_{2 y}\left(\theta_{\mathrm{s}}, u_{\mathrm{s}}, \varphi_{\mathrm{s}}\right)-R_{2 y}^{*}}{R_{2 y}^{\#}\left(\theta_{\mathrm{s}}^{\#}, u_{\mathrm{s}}^{\#}, \varphi_{\mathrm{s}}^{\#}\right)-R_{2 y}^{*}}=\frac{R_{2 z}\left(\theta_{\mathrm{s}}, u_{\mathrm{s}}, \varphi_{\mathrm{s}}\right)-R_{2 z}^{*}}{R_{2 z}^{\#}\left(\theta_{\mathrm{s}}^{\#}, u_{\mathrm{s}}^{\#}, \varphi_{\mathrm{s}}^{\#}\right)-R_{2 z}^{*}}
\end{array}\right.
$$

where $m$ is the module of the face gear pair and the other two points on the lines are located at the top and root of the tooth. The straight line is represented by the fifth and sixth formulas listed in Eq. (6). The direction angles measured from the straight line to axis $i 2(i=x, y, z)$ are represented with Eq. (7).

$$
\left\{\begin{array}{l}
\alpha_{x}=\arccos \left(R_{2 x}-R_{2 x}^{\#}\right) /\left|\boldsymbol{R}_{2}-\boldsymbol{R}_{2}^{\#}\right| \\
\alpha_{y}=\arccos \left(R_{2 y}-R_{2 y}^{\#}\right) /\left|\boldsymbol{R}_{2}-\boldsymbol{R}_{2}^{\#}\right| \\
\alpha_{z}=\arccos \left(R_{2 z}-R_{2 z}^{\#}\right) /\left|\boldsymbol{R}_{2}-\boldsymbol{R}_{2}^{\#}\right|
\end{array}\right.
$$

(3) After solving Eq. (5)-Eq. (7), the straight line could be represented by Eq. (8), where $x_{\mathrm{sl}}, y_{\mathrm{sl}}, z_{\mathrm{sl}}$ are the coordinates of the point on the straight line in $S_{2}$. In this step, $z_{\mathrm{sl}}$ is replaced with the tooth height, and $x_{\mathrm{sl}}$ and $y_{\mathrm{sl}}$ are solved with Eq. (8). Then, in the neighborhood of the 
straight line, any point on the surface $\Sigma_{2}$ is solved by Eq. (1) and Eq. (4), and the corresponding deviation is calculated by Eq. (9).

$$
\begin{aligned}
& \frac{x_{\mathrm{sl}}-R_{2 x}^{*}}{\cos \alpha_{x}}=\frac{y_{\mathrm{sl}}-R_{2 y}^{*}}{\cos \alpha_{y}}=\frac{z_{\mathrm{sl}}-R_{2 z}^{*}}{\cos \alpha_{z}}
\end{aligned}
$$

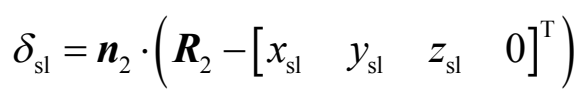

\subsection{Developable Ruled Surface for Face Gears}

The deviation represented in Eq. (9) and the differential angle in Section 2.5 are ignored here, and will be discussed in Section 2.5 and Section 5.1.

Comparing the instantaneous axis $O_{2} P$ in Fig. 1 and the special contact line $L_{2 \mathrm{~s}}$ in Fig. 2, their directions are consistent; in fact, at any point $Q$ on instantaneous axis $\mathrm{O}_{2} \mathrm{P}$, the linear velocities of the shaper and face gear are equal, which are represented as follows:

$$
r_{Q} \omega_{\mathrm{s}}=L_{Q} \omega_{2} \sin \gamma=\left(L_{Q} \omega_{\mathrm{s}} N_{\mathrm{s}} \sin \gamma\right) / N_{2}
$$

where $r_{Q}$ and $L_{\mathrm{Q}}$ are the distances from point $Q$ to axes $z_{\mathrm{s}}$ and $z_{2}$, respectively, and $\omega_{\mathrm{s}}$ and $\omega_{2}$ are the angular velocities of the shaper and face gear, respectively. As shown in Fig. 3, any point on the involute, $r_{Q}$ can be expressed as follows:

$$
\left\{\begin{array}{l}
r_{Q}=r_{\mathrm{bs}} / \cos \left(\theta_{\mathrm{s}}+\theta_{\mathrm{s} 0}\right) \\
\theta_{\mathrm{s} 0}=\pi /\left(2 N_{\mathrm{s}}\right)-\tan \alpha+\alpha
\end{array}\right.
$$

where $r_{\mathrm{bs}}=r_{\mathrm{ps}} \cos \alpha$ is the radius of the basic circle of the shaper and $\alpha$ is the pressure angle of the face gear pair. Hence, $L_{\mathrm{Q}}$ can be expressed as shown in Eq. (12).

$$
L_{Q}=r_{\mathrm{bs}} N_{2} /\left[N_{\mathrm{s}} \cos \left(\theta_{\mathrm{s}}+\theta_{\mathrm{s} 0}\right) \sin \gamma\right]
$$

In $S_{2}, L_{Q}$ represents the position of the origin $O_{\mathrm{a}}$ (Fig. 3) on the contact line $L_{2 \mathrm{~s}}$ (Fig. 2) in the longitudinal direction of the face gear tooth, and the instantaneous center of origin $O_{\mathrm{a}}$ is $Q$.

As shown in Fig. 2, the contact line $L_{2 s}$ could be regarded as a longitudinal generating line of the tooth surface for a face gear, and the profile curve is a straight line $s l$ that is tangent to $L_{2 s}$. In this way, a new tooth surface was designed for the face gear.
When viewed from the end face of the shaper, the contact line $L_{2 \mathrm{~s}}$ is an involute, as shown in Fig. 2 and Fig. 3. By taking Eq. (12) into consideration, the position and unit normal vectors $\boldsymbol{R}_{2}^{\mathrm{N}} \boldsymbol{n}_{2}^{\mathrm{N}}$ of the newly defined tooth surface $\Sigma_{2}^{\mathrm{N}}$ can be represented by the following formulas:

$$
\begin{gathered}
A=\left|O_{\mathrm{a}} O_{\mathrm{b}}\right|=r_{\mathrm{bs}} \tan \left(\theta_{\mathrm{s}}+\theta_{\mathrm{s} 0}\right)-r_{\mathrm{bs}} \theta_{\mathrm{s}} \\
L_{\mathrm{O}}=\left|O_{2} O_{\mathrm{s}}\right|=r_{Q} / \tan \gamma+L_{Q} \\
\boldsymbol{R}_{2}^{\mathrm{N}}\left(\theta_{\mathrm{s}}, u_{\mathrm{a}}\right)=\boldsymbol{M}_{2 \mathrm{~s}} \boldsymbol{M}_{\mathrm{sb}} \boldsymbol{M}_{\mathrm{ba}} \boldsymbol{R}_{\mathrm{a}}=\boldsymbol{M}_{2 \mathrm{a}} \boldsymbol{R}_{\mathrm{a}}= \\
{\left[\begin{array}{cccc}
1 & 0 & 0 & 0 \\
0 & -\cos \gamma & -\sin \gamma & -L_{\mathrm{O}} \sin \gamma \\
0 & \sin \gamma & -\cos \gamma & -L_{\mathrm{O}} \cos \gamma \\
0 & 0 & 0 & 1
\end{array}\right] \cdot\left[\begin{array}{cccc}
1 & 0 & 0 & 0 \\
0 & 1 & 0 & -r_{Q} \\
0 & 0 & 1 & 0 \\
0 & 0 & 0 & 1
\end{array}\right] .} \\
{\left[\begin{array}{cccc}
\cos \lambda & \sin \lambda & 0 & -A \cos \lambda \\
-\sin \lambda & \cos \lambda & 0 & A \sin \lambda \\
0 & 0 & 1 & 0 \\
0 & 0 & 0 & 1
\end{array}\right] \cdot\left[\begin{array}{c}
0 \\
u_{\mathrm{a}} \\
0 \\
1
\end{array}\right]} \\
\boldsymbol{n}_{2}^{\mathrm{N}}\left(\theta_{\mathrm{s}}, u_{\mathrm{a}}\right)=\left(\frac{\partial \boldsymbol{R}_{2}^{N}}{\partial \theta_{\mathrm{s}}} \times \frac{\partial \boldsymbol{R}_{2}^{N}}{\partial u_{\mathrm{a}}}\right) /\left|\frac{\partial \boldsymbol{R}_{2}^{N}}{\partial \theta_{\mathrm{s}}} \times \frac{\partial \boldsymbol{R}_{2}^{N}}{\partial u_{\mathrm{a}}}\right|
\end{gathered}
$$

where $\lambda=\theta_{\mathrm{s}}+\theta_{\mathrm{s} 0}, \boldsymbol{R}_{\mathrm{a}}$ represents the line tangent to the involute at the coordinate origin point $O_{\mathrm{a}}, u_{\mathrm{a}}$ is the distance between $O_{\mathrm{a}}$ and a current point, and $\boldsymbol{M}_{j i}(i=\mathrm{a}, \mathrm{b}, \mathrm{s} ; j=\mathrm{b}, \mathrm{s}, 2)$ is a matrix of coordinate transformations from system $S_{i}$ to $S_{j}$.

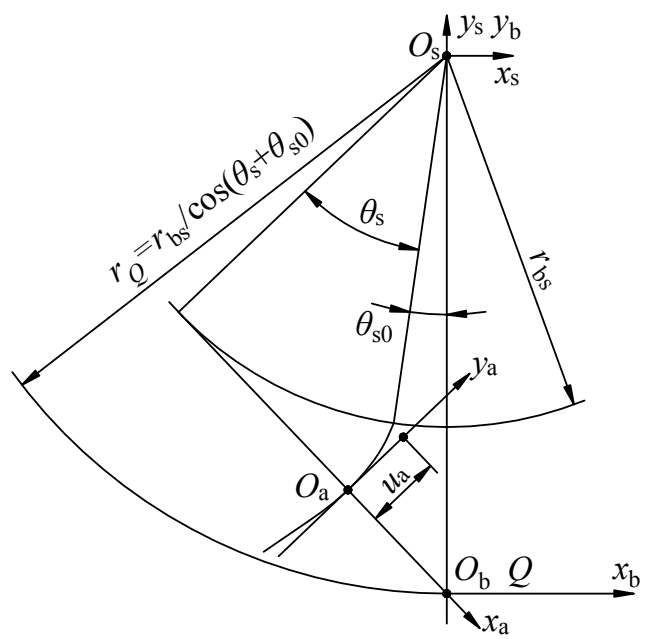

Figure 3 Involute and tangent line at any point

According to the information elaborated above, the essential differences between $\Sigma_{2}^{\mathrm{N}}$ and $\Sigma_{2}$ are as follows: (1) $\Sigma_{2}$ is an envelope of the family of surfaces $\Sigma_{\mathrm{s}}$, whereas $\Sigma_{2}^{\mathrm{N}}$ is a family of tangent lines used when creating the involute 
$L_{2 \mathrm{~s}}$ in surface $\Sigma_{\mathrm{s}}$; (2) $\Sigma_{2}$ is an undeveloped ruled surface, whereas $\Sigma_{2}^{\mathrm{N}}$ is a developable ruled surface according to the theory of differential geometry [17].

\subsection{Correction for the New Tooth Surface}

Because of the intersecting axes $z_{\mathrm{s}}$ and $z_{2}$ and the face gear rotating around $z_{2}$, in the $x_{\mathrm{a}} O_{\mathrm{a}} y_{\mathrm{a}}$ plane (Fig. 3), for the shaper, the normal vector of any point on the involute at any rotational angle can pass through instantaneous center $Q$, but for the face gear, the profile curve is defined as straight line $y_{\mathrm{a}}$ (or $s l$ ), on which one and only one point's normal vector at rotational angle $\varphi_{2}=\varphi_{\mathrm{s}}=0$ can pass through $Q$, the only one point is origin $O_{\mathrm{a}}$, when the straight line rotates with the face gear around axis $z_{2}$, at other rotational angle $\varphi_{2}=N_{2} \varphi_{\mathrm{s}} / N_{\mathrm{s}} \neq 0$, the point whose normal vector can passes throng $Q$, is conjugate with the involute, must locate either one side of the straight line with a certain arc length in the longitudinal direction, the rotation around axis $z_{2}$ causes the arc length of differential which creates the angle between lines $s l$ and $g l$. This angle is referred to as the differential angle because it reflects the differential arc length.

To simplify the manufacturing process of a face gear, it is not necessary to consider applying the differential angle to correct the new tooth surface $\Sigma_{2}^{\mathrm{N}}$. The reasons this is unnecessary are presented hereafter. (1) Obtaining good meshing performance is more important than pursuing microscopic precision. (2) A conventional face gear is not completely conjugated to its mating pinion because the pinion (number of teeth $=N_{1}$ ) has 1-3 fewer teeth than the shaper (number of teeth $=N_{\mathrm{s}}$ ) [1-2]. (3) Some types of gear drives do not have a standard or theoretical tooth surface, so the tooth surfaces are defined by the meshing performance [18-19]. This idea is also applicable to a face gear with a developable ruled surface. For example, the tooth surface of the pinion, which has fewer teeth and is easier to machine, could be redefined using the conjugation principle and then modified. (4) A small scale differential angle is not easy to control on the machine tool. Hence, another form of $\mathrm{NC}$ is needed to regulate the differential angle, thereby increasing the operational cost of the machine tool.

However, the differential angle is beneficial for reducing or minimizing the surface $\Sigma_{2}^{\mathrm{N}}$ deviation from $\Sigma_{2}$; therefore, the differential angle is presented here as a method to reduce the deviation of surface $\Sigma_{2}^{\mathrm{N}}$.

The differential angle, denoted $\alpha_{s l}$ in plane $y_{\mathrm{s}} O_{\mathrm{s}} z_{\mathrm{s}}$, is shown in Fig. 4, in which the involute and its tangent line and the profile line $g l$ of surface $\Sigma_{2}$ overlap on axis $y_{\mathrm{s}}$.
According to Fig. 4, surface $\Sigma_{2}^{\mathrm{N}}$ can be corrected as follows:

$$
\begin{gathered}
\left\{\begin{array}{l}
\alpha_{s l}=\alpha_{y}-\gamma \\
\boldsymbol{R}_{2}^{\mathrm{N}}\left(\theta_{\mathrm{s}}, u_{\mathrm{a}}\right)=\boldsymbol{M}_{2 \mathrm{~s}} \boldsymbol{M}_{\mathrm{sb}} \boldsymbol{M}_{\mathrm{bc}} \boldsymbol{M}_{\mathrm{ca}} \boldsymbol{R}_{\mathrm{a}}
\end{array}\right. \\
\boldsymbol{M}_{\mathrm{ca}}=\left[\begin{array}{cccc}
1 & 0 & 0 & 0 \\
0 & \cos \alpha_{s l} & -\sin \alpha_{s l} & 0 \\
0 & \sin \alpha_{s l} & \cos \alpha_{s l} & 0 \\
0 & 0 & 0 & 1
\end{array}\right]
\end{gathered}
$$

where $\boldsymbol{M}_{\mathrm{ca}}$ is a matrix of coordinate transformations from $S_{\mathrm{a}}$ to $S_{\mathrm{c}}\left(\boldsymbol{M}_{\mathrm{bc}}=\boldsymbol{M}_{\mathrm{ba}}\right)$. Eq. (17) could not eliminate the deviation absolutely because of different definitions between surfaces $\Sigma_{2}^{\mathrm{N}}$ and $\Sigma_{2}$.

\section{New Surface Cutting Method}

\subsection{Cutter Design}

Because $\Sigma_{2}^{N}$ is a developable ruled surface, a finger-shaped cutter, cylindrical milling cutter, cone disk milling cutter or planing cutter (shown in Fig. 5) could be used to machine a face gear with surface $\Sigma_{2}^{N}$. If the conical surface of the cone disk is covered with abrasive materials, it becomes a grinding wheel that could be used to grind the face gear.

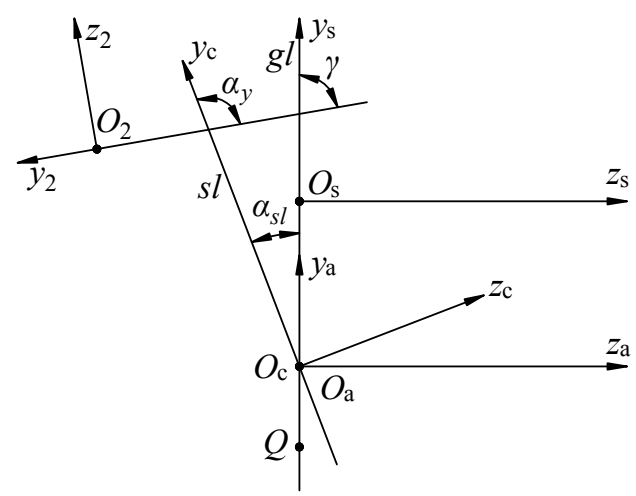

Figure 4 Sketch of the differential angle between lines $s l$ and $g l$

As planing is the most suitable approach to illustrate face gear generation with a straight-edged cutter, a planing cutter (Fig. 5 (d)) is used as an example to elaborate the manufacturing process.

The geometry of the planing cutter is shown in Fig. 5 (d). The cutting plane is denoted $\Pi_{1}$, which is similar to the cross section of a straight rack. The angle $\eta$ between planes 
$\Pi_{2}$ (or $\Pi_{3}$ ) and $\Pi_{1}$ should be less than $\pi / 2 \mathrm{rad}$; otherwise $\Pi_{2}$ (or $\Pi_{3}$ ) will interfere or cut the surface generated by $\Pi_{1}$. Hence, the best choice for the basic body of the planing cutter is a triangular pyramid.
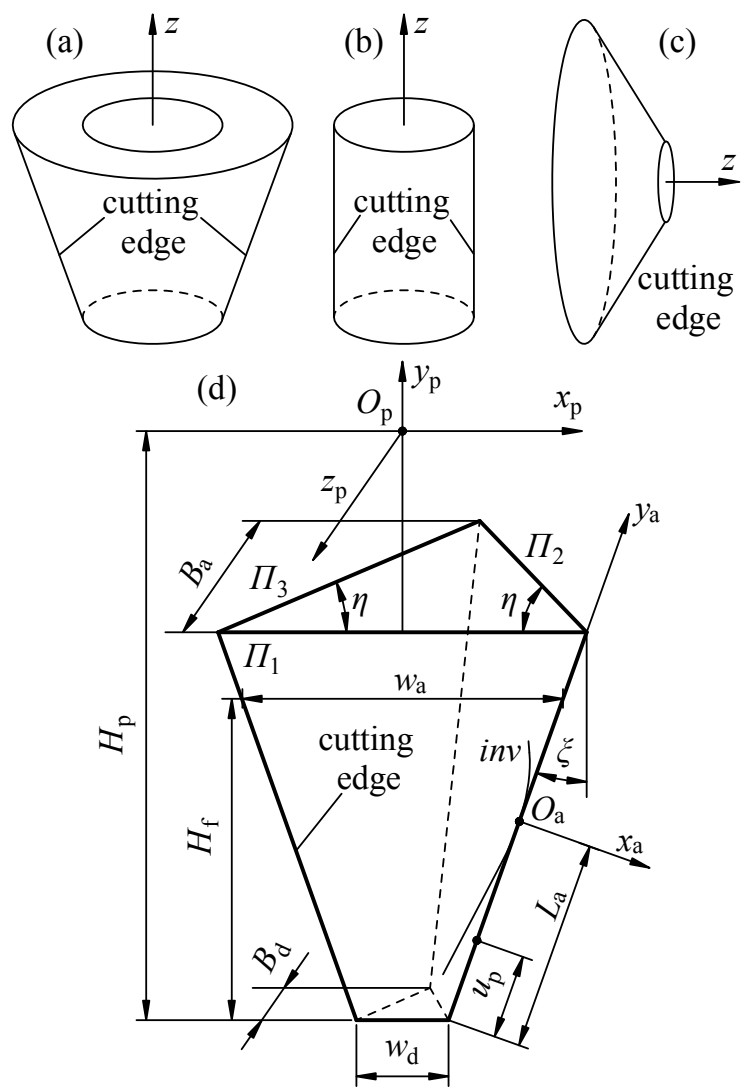

Figure 5 Suitable cutters for new tooth surface generation: (a) finger-shaped cutter, (b) cylindrical milling cutter, (c) cone disk milling cutter/grinding wheel, and (d) planing cutter

The parameters for the planing cutter are as follows: the cutter height $H_{\mathrm{f}}=2.25 \mathrm{~m}$; the cutting body and handle height $H_{\mathrm{p}}$ are constrained by the machine tool; the bottom width $w_{\mathrm{d}}$ and top width $w_{\mathrm{a}}$ are equal to the tooth space widths of the outer root and inner top of the face gear, respectively; the bottom thickness $B_{\mathrm{d}}$ and top thickness $B_{\mathrm{a}}$ are determined by the cutter strength and cutting force (generally $B_{\mathrm{d}} \leq B_{\mathrm{a}}$ ); the inclination angle $\xi$ of the side edge should satisfy $\tan \xi=0.5\left(w_{\mathrm{a}}-w_{\mathrm{d}}\right) / H_{\mathrm{f}}$, but this is not compulsory; $u_{\mathrm{p}}$ is the distance from a current point on the cutting edge to the cutter bottom, according to Fig. 5 (d); and the position vector of the cutting edge in $S_{\mathrm{p}}$ is expressed as follows:

$$
\boldsymbol{R}_{\mathrm{p}}=\left[\begin{array}{llll}
w_{\mathrm{d}} / 2+u_{\mathrm{p}} \sin \xi & -H_{\mathrm{p}}+u_{\mathrm{p}} \cos \xi & 0 & 1
\end{array}\right]^{\mathrm{T}}
$$

In the generation process, only the cutting edge works, so it is not necessary to give the normal vector of any surface or plane on which the cutting edge is located.

\subsection{Rules of Planing Motion}

As shown in Fig. 1, Fig. 2, and Eq. (15), the planing cutter can generate surface $\Sigma_{2}^{\mathrm{N}}$, during which the cutter only needs three translations and a rotation. These translations alter the position of the cutter in direction $i 2(i=x, y, z)$, whereas the rotation changes the tilting angle of the cutting edge of the cutter. After two side surfaces of a tooth are generated, the workpiece indexes, and another rotation is performed.

Fig. 6 shows the structure of a 5 -axis NC planer. The axes correspond to translations in the $X, Y$, and $Z$ directions and rotations in the $B$ and $C$ directions. Therefore, the planer provides sufficient degrees of freedom to manufacture a face gear with a tooth surface $\Sigma_{2}^{\mathrm{N}}$, thereby illustrating the advantages and convenience of this approach in machining face gears with a developable ruled surface $\Sigma_{2}^{\mathrm{N}}$. The planer shown in Fig. 6 is suitable for machining gears with an orthogonal face without loss of generality. If a nonorthogonal face gear is considered, a special fixture is needed to adjust the axis angle $\gamma$.

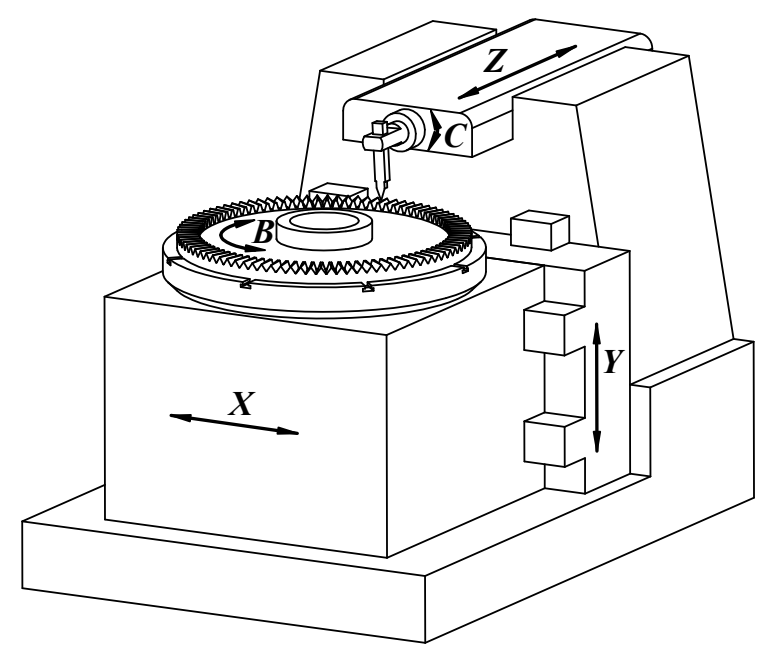

Figure 6 Five-axis NC planer used for face gear generation

The motion rules of the NC planer should be determined before cutting the workpiece. The equivalent principle generally used in the determination of the $\mathrm{NC}$ motion rules is that the position and direction of the surface generated in the $\mathrm{NC}$ cutting process is identical to that in the abstract or uniform generation process [20]. Considering the structure (Fig. 5 (d)) of the cutting tool, the abstract generation is completely expressed by Eq. (20) and Eq. (21), where $\boldsymbol{M}_{\text {ap }}$ 
is the coordinate transformations from $S_{\mathrm{p}}$ to $S_{\mathrm{a}}$ and $L_{\mathrm{a}}$ is the distance from the coordinate origin $O_{\mathrm{a}}$ to the tool bottom.

As the coordinate origin $O_{\mathrm{a}}$ is a moving point (Fig. 3), the distance $L_{\mathrm{a}}$ is a variable parameter (Fig. 5). To determine $L_{\mathrm{a}}$, the bottom of the planing cutter must be able to cut the tooth root and the tooth height in the direction $z_{2}$, as shown in Eq. (15). Hence, $L_{\mathrm{a}}$ can be solved with Eq. (22).

$$
\boldsymbol{R}_{2}^{\mathrm{N}}\left(\theta_{\mathrm{s}}, u_{\mathrm{a}}\right)=\boldsymbol{M}_{2 \mathrm{~s}} \boldsymbol{M}_{\mathrm{sb}} \boldsymbol{M}_{\mathrm{ba}} \boldsymbol{M}_{\mathrm{ap}} \boldsymbol{R}_{\mathrm{p}}=\boldsymbol{M}_{2 \mathrm{p}} \boldsymbol{R}_{\mathrm{p}}
$$

$$
\begin{aligned}
& \boldsymbol{M}_{\text {ap }}= \\
& {\left[\begin{array}{cccc}
\cos \xi & -\sin \xi & 0 & -w_{\mathrm{d}} \cos \xi / 2-H_{\mathrm{p}} \sin \xi \\
\sin \xi & \cos \xi & 0 & -w_{\mathrm{d}} \sin \xi / 2+H_{\mathrm{p}} \cos \xi-L_{\mathrm{a}} \\
0 & 0 & 1 & 0 \\
0 & 0 & 0 & 1
\end{array}\right]} \\
& L_{\mathrm{a}}=-u_{\mathrm{a}}=\left[\left(r_{\mathrm{ps}}+1.25 m\right) / \sin \gamma+A \sin \gamma .\right. \\
& \left.\sin \lambda-r_{Q} \sin \gamma\right] / \cos \lambda
\end{aligned}
$$

The coordinate systems for the planer are shown in Fig. 7. Herein, it is assumed that the zero cutting point of the $\mathrm{NC}$ program is the coordinate origin $O_{2}$, the systems $S_{\mathrm{p}}$ and $S_{2}$ are rigidly connected to the planing cutter and the face gear, auxiliary systems $S_{\mathrm{d}}, S_{\mathrm{e}}$ are connected to the frame of the planer. Note that $C_{X}, C_{Y}$, and $C_{Z}$ are three coordinates for the translational axes, $C_{C}$ is the rotational axis. The matrix of coordinate transformations from $S_{\mathrm{p}}$ to $S_{2}$ is represented by Eq. (23). The equivalent principle of the planing example is shown in Eq. (24), in which two matrices are compared; the coordinates could be solved as shown in Eq. (25).

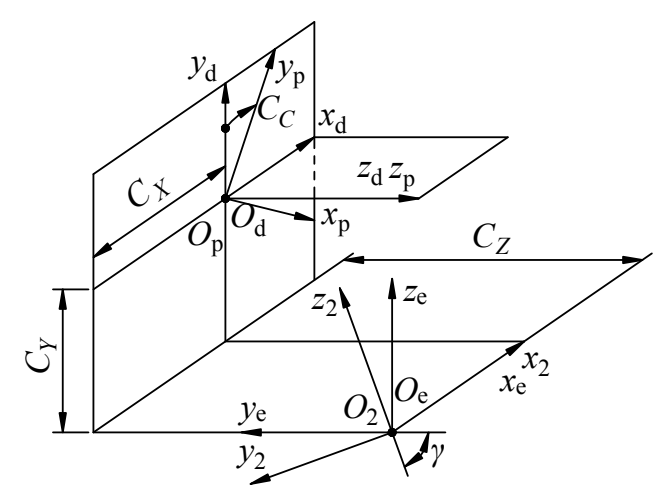

Figure 7 Coordinate systems for face gear generation

The translational and rotational coordinates are functions of the generating parameter $\theta_{\mathrm{s}}\left(\lambda=\theta_{\mathrm{s}}+\theta_{\mathrm{s} 0}\right)$; these coordinates will be used to program the NC codes.

$$
\begin{aligned}
& \boldsymbol{M}_{2 \mathrm{p}}^{\mathrm{C}}= \\
& \left\{\begin{array}{l}
{\left[\begin{array}{cccc}
\cos C_{C} & \sin C_{C} & 0 & C_{X} \\
\cos \gamma \sin C_{C} & -\cos \gamma \cos C_{C} & -\sin \gamma & e_{24} \\
-\sin \gamma \sin C_{C} & \sin \gamma \cos C_{C} & -\cos \gamma & e_{34} \\
0 & 0 & 0 & 1
\end{array}\right]} \\
e_{24}=C_{Z} \sin \gamma-C_{Y} \cos \gamma \\
e_{34}=C_{Z} \cos \gamma+C_{Y} \sin \gamma
\end{array}\right. \\
& \boldsymbol{M}_{2 \mathrm{p}}^{\mathrm{C}}=\boldsymbol{M}_{2 \mathrm{p}} \\
& C_{C}=\lambda-\xi \\
& C_{X}=H_{\mathrm{p}} \sin (\lambda-\xi)-w_{\mathrm{d}} \cos (\lambda-\xi) / 2- \\
& \left\{C_{Y}=H_{\mathrm{p}} \cos (\lambda-\xi)+w_{\mathrm{d}} \sin (\lambda-\xi) / 2-\right. \\
& L_{\mathrm{a}} \cos \lambda+A \cos \lambda-r_{Q} \\
& C_{Z}=-L_{\mathrm{O}}
\end{aligned}
$$

\section{Surface Crowning and TCA Algorithm}

\subsection{Double Crowning of the New Tooth Surface}

From the aspect of manufacturing, a face gear with the newly defined tooth surface is an optimization alternative; note that good meshing performance is a requirement in this study. In the face gear with surface $\Sigma_{2}$ generated by a shaper, the contact lines between the generating and generated surfaces under rotational angle $\varphi_{2}=N_{\mathrm{s}} \varphi_{\mathrm{s}} / N_{2} \neq 0$ are approximately parallel to the special contact line $L_{2 \mathrm{~s}}$. Considering the defined pattern (Fig. 2 and Fig. 3) of the new tooth surface, which meshes with the surface of the pinion when $N_{1}=N_{\mathrm{s}}$, the two surfaces may be approximately in line contact, indicating that it is necessary to modify the tooth surface to localize the bearing contact.

Many methods have been investigated to provide better control of meshing performance [21-23], such as local synthesis and active design. However, the aims of the paper mainly focus on the proposal of the new tooth surface and its generation for a face gear. Hence, the simplest method - parabolic modification - is selected here to demonstrate that the newly defined tooth surface could obtain acceptable good meshing performance. The corresponding modification can be performed on the face gear or the pinion [5, 24]; for the sake of brevity, the modification is only performed on the face gear in this study. 

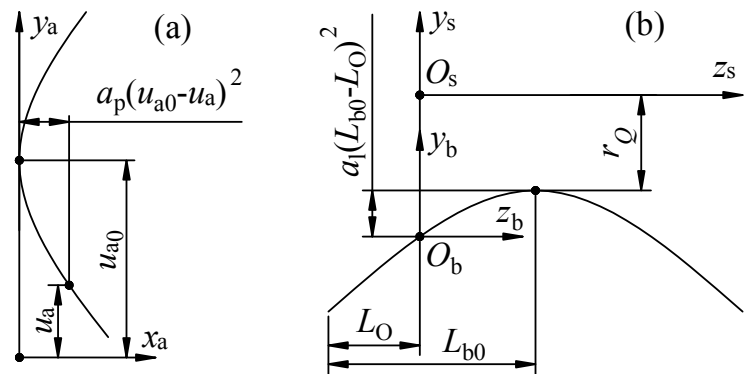

Figure 8 Double crowning for the newly defined tooth surface

The crowning profile for the newly defined tooth surface is shown in Fig. 8 (a), wherein $a_{\mathrm{p}}$ is the parabola coefficient in the profile direction, $u_{\mathrm{a} 0}$ is used to control the position of the parabola vertex, and the vector $\boldsymbol{R}_{\mathrm{a}}$ in Eq. (15) is replaced with Eq. (26). Fig. 8 (b) shows the longitudinal crowning, wherein $a_{1}$ is the parabola coefficient of the plunging trajectory of the coordinate origin $O_{\mathrm{b}}$ and $L_{\mathrm{b} 0}$ is the distance from the coordinate origin $\mathrm{O}_{2}$ to the parabola vertex, which determines the position of the longitudinal parabola vertex. Therefore, the matrix $\boldsymbol{M}_{\mathrm{sb}}$ in Eq. (15) changes to the form shown in Eq. (27).

$$
\begin{aligned}
& \boldsymbol{R}_{\mathrm{a}}=\left[\begin{array}{llll}
a_{\mathrm{p}}\left(u_{\mathrm{a} 0}-u a\right) & u_{\mathrm{a}} & 0 & 1
\end{array}\right]^{\mathrm{T}} \\
& \boldsymbol{M}_{\mathrm{sb}}=\left[\begin{array}{cccc}
1 & 0 & 0 & 0 \\
0 & 1 & 0 & -r_{Q}-a_{1}\left(L_{\mathrm{b} 0}-L_{\mathrm{O}}\right) \\
0 & 0 & 1 & 0 \\
0 & 0 & 0 & 1
\end{array}\right]
\end{aligned}
$$

\subsection{TCA Algorithm}

The meshing performance is simulated by tooth contact analysis. Litvin established coordinate systems and tangent contact equations for a simulation of the meshing and contact of face gear pairs. These achievements, which are described in detail in [1-2], are used directly in this study to show the performance of the newly defined tooth surface and its modified face gear when meshed with the involute surface of the pinion.

\section{Numerical Examples and Discussion}

This section presents the numerical results, including (1) the deviation of the new tooth surface of the face gear, (2) the manufacturing simulation of the newly defined tooth surface and its deviation, and (3) the meshing performance of the new surface determined by TCA. The main parameters of the face gear pair are listed in Table 1, but some parameters will take different values in different numerical examples.

Table 1 Parameters of the face gear pair

\begin{tabular}{lll}
\hline Parameter & Symbol & Value (units) \\
\hline Number of teeth in the pinion & $N_{1}$ & 30 \\
Number of teeth in the shaper & $N_{\mathrm{s}}$ & 30 \\
Number of teeth in the face gear & $N_{2}$ & 160 \\
Module & $m$ & $6.35(\mathrm{~mm})$ \\
Pressure angle & $\alpha$ & $20\left(^{\circ}\right)$ \\
Shaft angle & $\gamma$ & $90\left(^{\circ}\right)$ \\
Internal (toe) radius & $L_{1}$ & $478(\mathrm{~mm})$ \\
Outer (heel) radius & $L_{2}$ & $567(\mathrm{~mm})$ \\
\hline
\end{tabular}

\subsection{New Tooth Surface Deviation}

(A) Deviation in the straight profile line. Based on Eq. (5) and Eq. (6), the straight line $s l$ can be determined, and its direction angles are shown in Fig. 9. Note that $\alpha_{x}$ and $\alpha_{z}$ can be regarded as the pressure angle and transmission angle on the cross section perpendicular to axis $z_{2}$, respectively. These angles vary with respect to the radius $L$, and their sum is approximately equal to $90^{\circ}$. Note that $\alpha_{y}$ reflects when $s l$ is nearly perpendicular to coordinate axis $z_{2}$. The differential angle change with respect to the generating angle $\theta_{\mathrm{s}}$ is shown in Fig. 12. The maximal and minimum differential angles respectively do not exceed $1^{\circ}$ and $-4^{\circ}$.

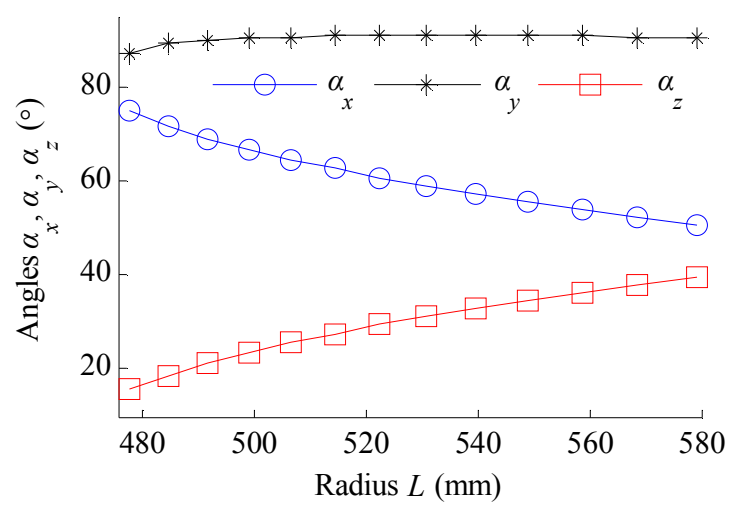

Figure 9 Direction angles of the straight profile line

The deviation between the straight profile line $s l$ and the conventional tooth surface $\Sigma_{2}$ of the face gear is calculated by using Eq. (8) and Eq. (9), and the results are shown in Fig. 10. The maximal deviation occurs at the corner of the root toe, which is the undercutting area, and the deviation in the rest of the area away from the corner and root approaches $0 \mu \mathrm{m}$. Hence, the results imply that apart from 
the root toe, the profile curve of the conventional tooth surface $\Sigma_{2}$ of the face gear can be regarded as an approximately straight line.

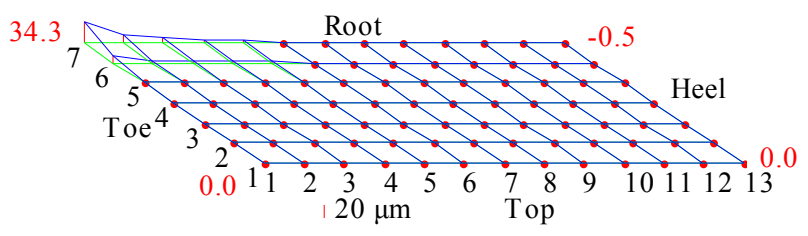

Max: $34.3 \mu \mathrm{m}$; Min: $-0.5 \mu \mathrm{m}$

Figure 10 Deviation in the straight profile line

(B) Deviation in the new developable ruled surface. Neglecting the differential angle of the straight profile line, Eq. (15) can be used to define a new tooth surface $\Sigma_{2}^{N}$ for the face gear. By applying the normal deviation of surfaces (similar to that in Eq. (9)), the deviation between $\Sigma_{2}^{\mathrm{N}}$ and $\Sigma_{2}$ is evaluated, and the results are shown in Fig. 11. The maximum deviation occurs at the root toe, which is similar to the results shown in Fig. 10; however, the magnitude of the deviation increases in Fig. 11. Furthermore, a minimum deviation is smaller than that shown in Fig. 10 at the top heel. In general, the deviation along the diagonal from the root of the toe to the top of the heel is larger than that along the diagonal from the top of the toe to the root of the heel.

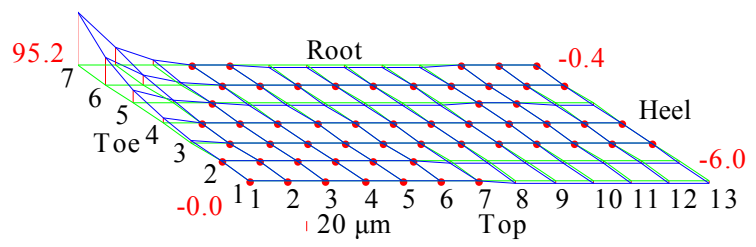

Max: $95.2 \mu \mathrm{m}$; Min: $-6.0 \mu \mathrm{m}$

Figure 11 Deviation in the developable ruled surface

Two things should be emphasized. (1) Undercutting leads to divergence of the solution, which has an influence on the accuracy of the deviation at the root toe, and increasing the internal radius or eliminating the undercutting surface will reduce the deviation and improve the accuracy of the solution. (2) The deviation along the diagonal from the root of the toe to the top of the heel decreases as the gear ratio $N_{2} / N_{\mathrm{s}}$ increases $\left(N_{2}=160\right.$ in Fig. 11, whereas $N_{2}=90$ in Fig. 15 (a)), and as the number of teeth increases, the face gear becomes increasingly similar to a rack.

(C) Deviation in the new developable ruled surface after correction. The differential angle of the straight profile line can be considered a function of the generating angle $\theta_{\mathrm{s}}$. The function is determined by the least squares method, and the solved data and the function are shown in Fig. 12.
Then, the function is applied in the correction of the new surface.

Fig. 13 shows the correction results. The maximal and minimal errors of 9.0 and $-14.6 \mu \mathrm{m}$, respectively, occur at points $i j=71$ and $51(i=1,2, \ldots, 7 ; j=1,2, \ldots, 13)$, which are located at the root toe. The correction reduces the deviation by more than a factor of $6(95.2 / 14.6=6.52)$. Therefore, the differential angle is very useful for reducing the deviation, which will increase the complexity of the machining tool and the difficulty of controlling the differential angle on the machine. In some cases, the amount of tooth surface modification [25] exceeds the deviation shown in Fig. 11. For these cases, we recommend ignoring the differential angle and the deviation in the developable ruled surface, and the adverse effects could be compensated by surface crowning, a conjugated pinion design, or limiting the internal radius.

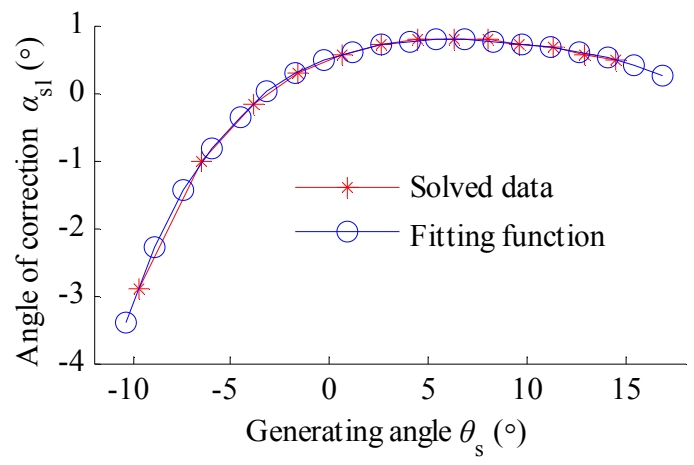

Figure 12 Differential angle of the straight profile line

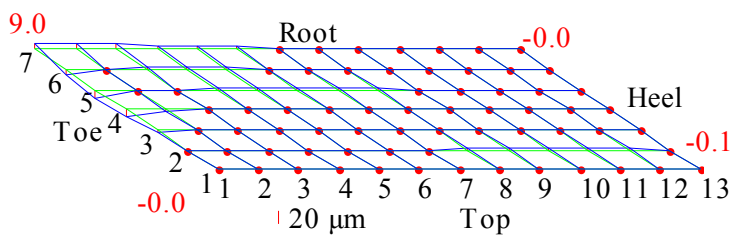

Max: $9.0 \mu \mathrm{m}$; Min: $-14.6 \mu \mathrm{m}$

Figure 13 Deviation in surface $\Sigma_{2}^{\mathrm{N}}$ after correction

\subsection{Manufacturing Simulation}

The purpose of this section is to show the process and advantages of the face gear manufactured by a cutter with a straight cutting edge, including the simplicity of the cutter, the high efficiency and precision of the generation.

To illustrate the influence of the number of teeth on the deviation and avoid display images that are too small due to the large scale of the workpiece, the number of teeth of the face gear is decreased. The parameters of the modified face gear and the cutter are listed in Table 2. 
Table 2 Parameters of the modified face gear and the cutter

\begin{tabular}{lll}
\hline Items & Symbol & Value (units) \\
\hline (A) Modified face gear & & \\
Number of teeth in the face gear & $N_{2}$ & 90 \\
Internal (toe) radius & $L_{1}$ & $273(\mathrm{~mm})$ \\
Outer (heel) radius & $L_{2}$ & $319(\mathrm{~mm})$ \\
(B) Cutter & & \\
Angle between cutting and coast flank & $\eta$ & $50.5\left({ }^{\circ}\right)$ \\
Cutter height & $H_{\mathrm{f}}$ & $14.3(\mathrm{~mm})$ \\
Cutting body and handle height & $H_{\mathrm{p}}$ & $170(\mathrm{~mm})$ \\
Bottom width & $w_{\mathrm{d}}$ & $1.6(\mathrm{~mm})$ \\
Top width & $w_{\mathrm{a}}$ & $12(\mathrm{~mm})$ \\
Bottom thickness & $B_{\mathrm{d}}$ & $1(\mathrm{~mm})$ \\
Top thickness & $B_{\mathrm{a}}$ & $12(\mathrm{~mm})$ \\
Side edge inclination angle & $\xi$ & $20\left({ }^{\circ}\right)$ \\
\hline
\end{tabular}

Fig. 14 shows the full appearance of the cutter, whose simplicity is mainly reflected in two aspects: the cutting edge is a straight line rather than a helix involute constrained by the shape of the shaper, and the cutting body (shown in Fig. 5) could be mounted on a rectangular handle like that of a lathe.

Based on Eq. (25), the $\mathrm{NC}$ codes for the face gear cutting are obtained, and the codes are applied when performing the cutting simulations and error tests on the VERICUT platform. Fig. 14 shows the simulation interface, part of the codes, virtual machine tool, cutter and machining work-piece. A video of the cutting simulation for the proposed method is available on the web: https://v.qq.com/x/page/z3133gsj38v.html

The high cutting efficiency is mainly reflected by the rough and finish cutting: a rough cut slot of full tooth height is shown on the right of the cutter in Fig. 14. In this process, assuming the cutter has sufficient strength, the two flanks of the tooth slot, such as a rack space, could be cut by only one back and forth translation in the longitudinal direction, and the process does not require the generating motion. The finished cut slot is shown on the left of the cutter in Fig. 14. One flank of the full height slot needs one back and forth translation with the generating motion, the efficiency increases considerably because the translation and generation are correlated and successive, and the cutter does not intermittently stay at individual positions along the tooth width to generate the tooth from the top to the root.

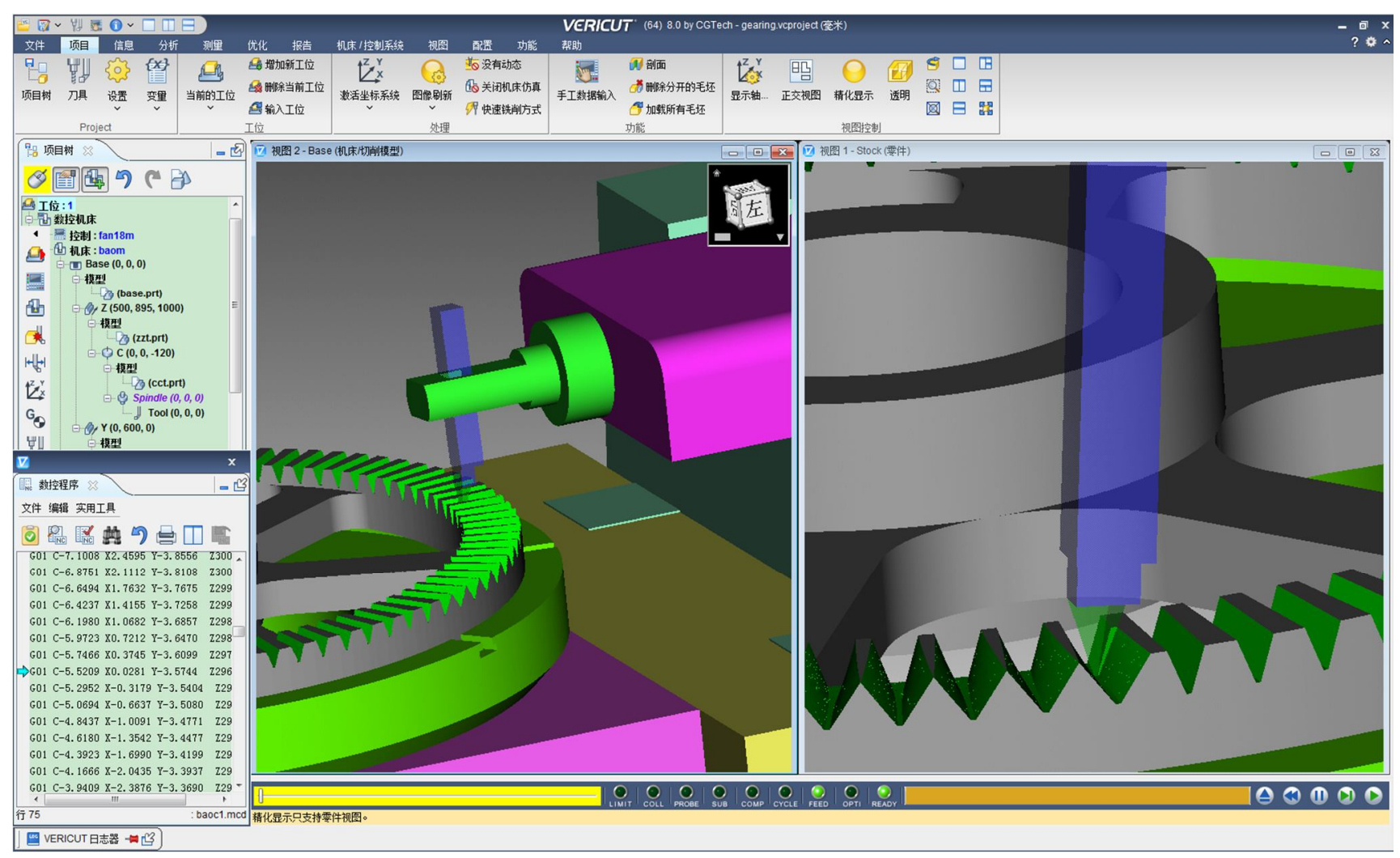

Figure 14 Cutting simulation for the face gear using VERICUT (its video is on the web: https://v.qq.com/x/page/z3133gsj38v.html)

The total deviation between the newly defined developable ruled surface $\Sigma_{2}^{N}$ and the theoretical one $\Sigma_{2}$ of the face gear is the sum of the principle deviation (shown in Fig. 15 (a)) and the machined deviation (Fig. 15 (c)). 
After the cutting simulation, the finished face gear is exported as an STL file, as shown in Fig. 15 (b). The topography of the newly defined surface shown in the figure is the measuring benchmark, and the coordinates of the STL model at the node of the topography are extracted to evaluate the deviation in the machined surface. Fig. 15 (c) shows the results; on the left flank, the maximal deviation is $-0.0 \mu \mathrm{m}$ and the minimal deviation is $-5.4 \mu \mathrm{m}$, whereas on the right flank, the maximal deviation is 4.5 $\mu \mathrm{m}$ and the minimal deviation is $0.0 \mu \mathrm{m}$. These errors, which could be caused by errors in the simulation and model transformation (e.g., in VERICUT, the tolerances of the interpolation and model transformation from VERICUT to STL are $0.05 \mathrm{~mm}$ ), are sufficiently small to confirm the correctness and feasibility of the face gear machining method.

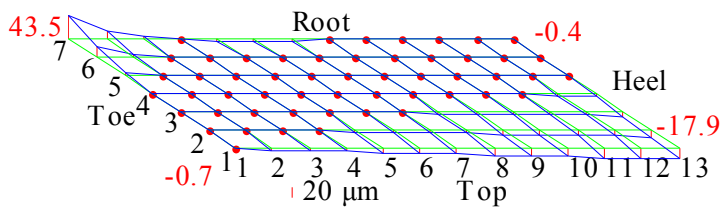

Max: $43.5 \mu \mathrm{m}$; Min: $-18.0 \mu \mathrm{m}$

(a) Principle deviation

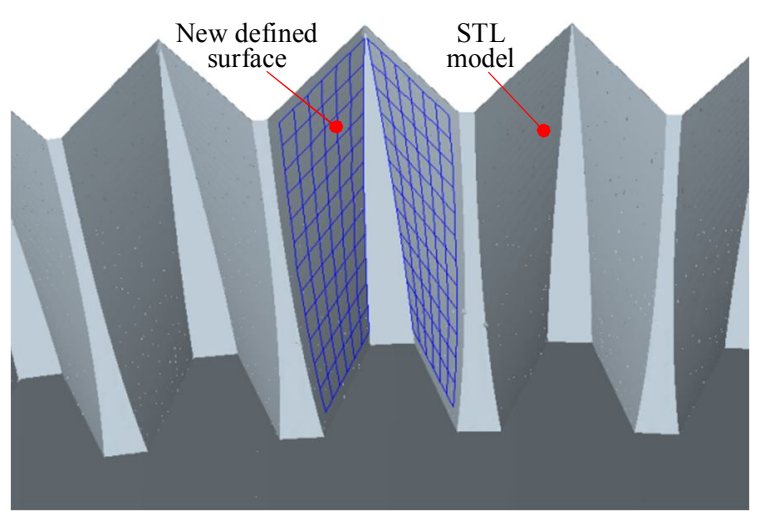

(b) STL model and topography for measurements

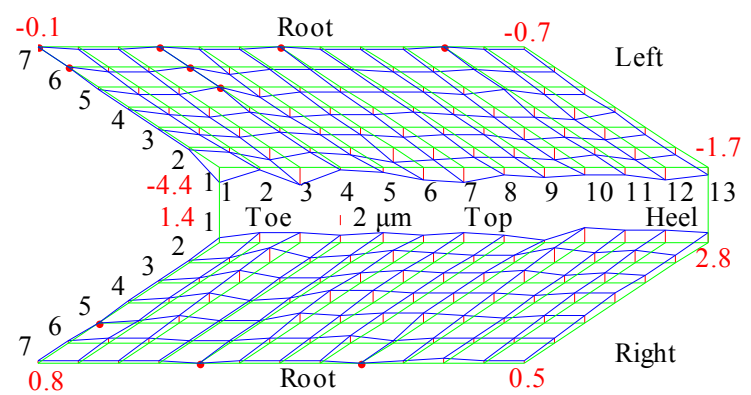

Left Max: -0.0 $\mu \mathrm{m}$; Left Min: $-5.4 \mu \mathrm{m}$; Right Max: $4.5 \mu \mathrm{m}$; and Right Min: $0.0 \mu \mathrm{m}$

(c) Topographic deviations in the machined STL model

Figure 15 Results of the simulated tooth surface
Then, the machining precision of the face gear generated by the straight-edged cutter could be elaborated as follows. (1) If the developable ruled surface $\Sigma_{2}^{\mathrm{N}}$ is defined as the face gear surface, the surface deviation does not exist. Therefore, it is very easy to obtain high precision due to the simplicity of the cutter and machining process. (2) If $\Sigma$ ${ }_{2}^{N}$ is compared with the theoretical conventional surface $\Sigma_{2}$, the surface deviation depends on the principle deviation. Even when undercutting is taken into consideration, the absolute deviation of the gear pair does not exceed $2 \%$ $(0.0952 / 6.35=0.01499$, taking Fig. 11 for example) of the gear pair module.

\subsection{Surface Meshing Simulation}

This section illustrates the meshing performance of the newly defined tooth surface $\Sigma_{2}^{\mathrm{N}}$ of the face gear meshed with the theoretical involute surface $\Sigma_{1}$ of the spur pinion and subsequently determines whether surface $\Sigma_{2}^{\mathrm{N}}$ is able to or has the potential to obtain acceptable meshing performance, which is simulated by TCA. Four design cases, including surface crowning, whose parameters are reported in Table 3, are used to show the meshing performance; the other parameters are identical to those in Table 1. Because the aligned installation is sufficient to illustrate the meshing quality, the misalignment is not taken into consideration.

In case 1 , the surface $\Sigma_{2}^{N}$ is meshed with $\Sigma_{1}$ of the pinion, for which the number of teeth is equal to the number of the teeth of the shaper and there is no surface crowning. In Fig. 16 (a), case 1 shows edge contact between the tooth root of the pinion and the tooth top of the face gear, whereas in Fig. 16 (c), case 1 shows small-scale intermittent transmission errors. This phenomenon can occur because the deviation (Fig. 11) between $\Sigma_{2}^{\mathrm{N}}$ and $\Sigma_{2}$ is sufficiently small (the absolute deviation is less than $6 \mu \mathrm{m}$ except for undercutting area $i \geq 4, j \leq 3, i=1,2, \ldots, 7 ; j=1,2, \ldots, 13) ; \Sigma_{2}^{\mathrm{N}}$ is approximately conjugated to $\Sigma_{1}$.

Table 3 Parameters for the meshing simulation

\begin{tabular}{lllll}
\hline Parameter & Case 1 & Case 2 & Case 3 & Case 4 \\
\hline$N_{\mathrm{s}}$ & 30 & 30 & 30 & 30 \\
$N_{1}$ & 30 & 28 & 30 & 30 \\
$a_{\mathrm{p}}$ & - & - & - & 0.00008 \\
$u_{\mathrm{a} 0}$ & - & - & - & $-30(\mathrm{~mm})$ \\
$a_{1}$ & - & - & 0.0001 & 0.0001 \\
$L_{\mathrm{b} 0}$ & - & - & $530(\mathrm{~mm})$ & $530(\mathrm{~mm})$ \\
\hline
\end{tabular}

The number of teeth of the pinion in case 2 is reduced to 

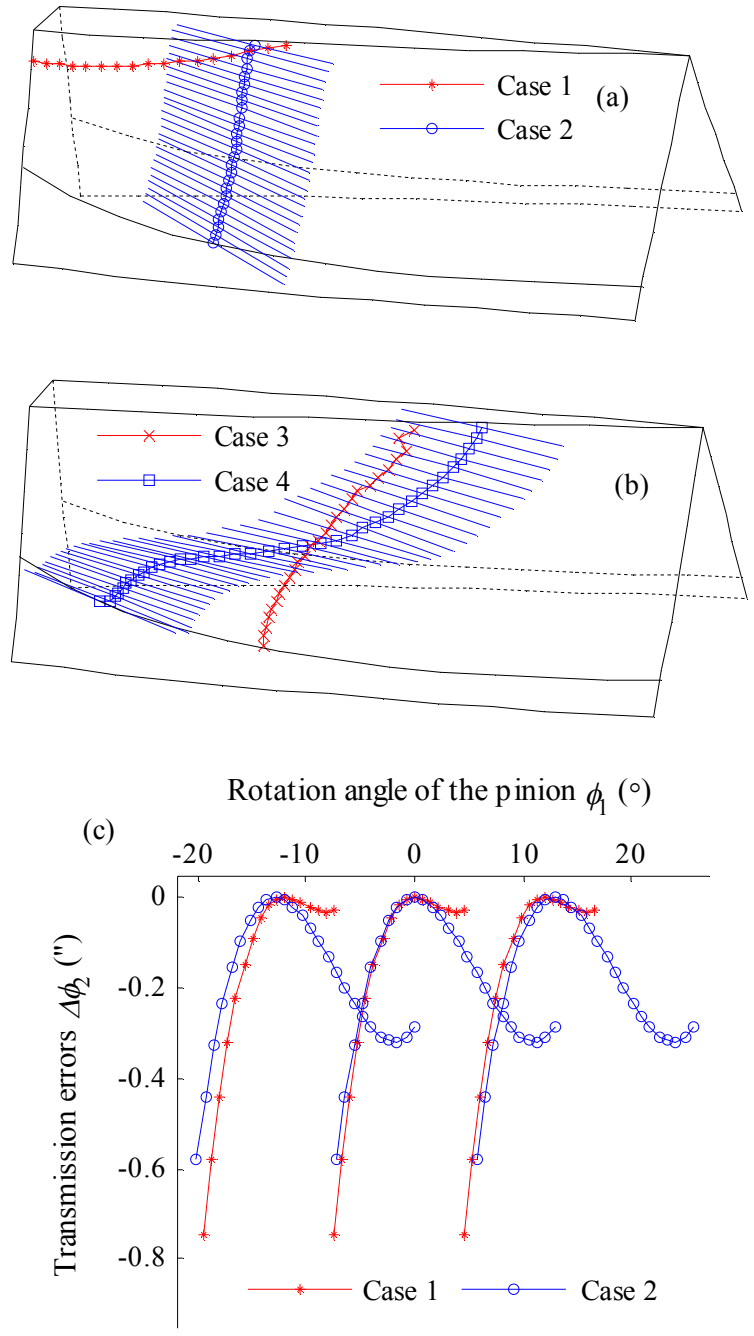

(d)

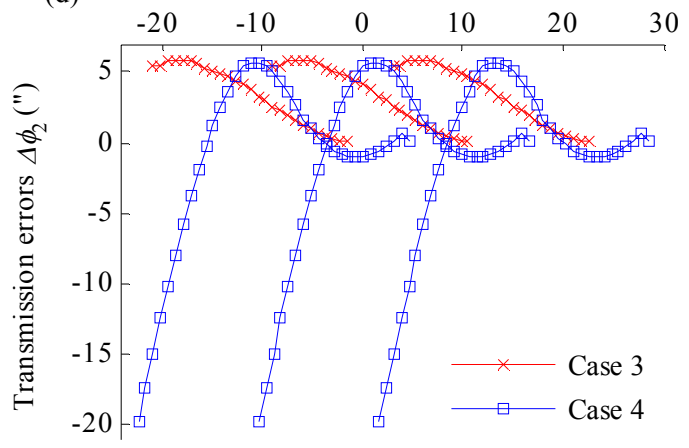

Figure 16 Results of meshing and contact simulation

28, and the contact pattern (Fig. 16 (a), case 2) of $\Sigma_{2}^{\mathrm{N}}$ meshed with $\Sigma_{1}$ extremely resembles that of $\Sigma_{2}$ rolling with the same $\Sigma_{1}$, but the transmission errors are different. The former (Fig. 16 (c), case 2) presents as a kind of higher-order function. At tooth replacement, the errors overlap each other, but the range is on a small scale, and the latter is a linear function equal to 0 [26]. The reason why $\Sigma_{2}^{\mathrm{N}}$ can correctly roll with $\Sigma_{1}$ is still the sufficiently small deviation (Fig. 11), which is reflected by the transmission errors.

The bearing contact of case 3 in Fig. 16 (b) is localized by longitudinal crowning, and the number of pinion teeth in cases 1 and 3 are the same. A comparison of the contact paths in cases 1 and 3 illustrates that the obvious localization is located at the center of the surface, reflecting that the two surfaces mainly contact the profile direction. The transmission errors in case 3 , as shown in Fig. 16 (d), are intermittent and linear within a certain range, and this kind of transmission error may cause severe vibration and noise [26-27].

Performing profile modification on the surface with longitudinal crowning in case 3 generates a double-crowned surface $\Sigma_{2}^{N}$ in case 4 , in which the meshing of $\Sigma_{2}^{\mathrm{N}}$ and $\Sigma_{1}$ shows the contact in both profile and longitudinal directions, as illustrated in Fig. 16 (b). The contact path is a curve with a slow variation, which begins at the root toe and terminates at the top heel. The transmission errors in case 4 (shown in Fig. 16 (d)) are a successive higher-order function, whose overlap at tooth replacement will lower the level of vibration and noise [26-27].

The mentioned results of the meshing performance of the newly defined surface $\Sigma_{2}^{\mathrm{N}}$ for the face gear are sufficient to illustrate that $\Sigma_{2}^{N}$ is able to obtain good meshing quality by selecting appropriate parameters or performing surface modification except when the gear ratio $N_{2} / N_{1}<3$, in which, if the developable ruled surface is defined as the tooth flank of the face gear, it is necessary to redesign the pinion based on the conjugate method and eliminate the adverse effects caused by large surface deviation on meshing performance.

\section{Conclusions}

To improve the uniformity of the cutter and increase production efficiency, a method of using a straight-edged cutter, such as a planing cutter, for face gear manufacturing is proposed. Based on the research performed, the following conclusions may be drawn:

(1) Based on the features of the conventional theoretical tooth surface of a face gear, assuming the profile curve of the surface is a straight line (the deviation from the surface shows that this assumption is valid), a new developable ruled surface could be defined as the face gear tooth flank. 
(2) A mathematical model of the new surface is presented, and the differential angle of the straight profile line is useful for reducing deviation between the conventional and new surfaces. However, because the deviation is very small except for in the undercutting area and the manufacturing difficulty will increase, it is not recommended to correct the new surface.

(3) A method of using a straight-edged cutter-in this case, a planing cutter-is proposed for generating the new surface. The model of the cutter and the corresponding motion rules are presented, through which the new surface generation is simulated by VERICUT. The results illustrate the simplicity and high production efficiency of the cutter and precision of the generated surface. Even when the principle deviation is added to the machined deviation, the absolute deviation is on the microscale.

(4) The meshing and contact simulation shows that the new surface rolls with the theoretical involute surface of the pinion, and when appropriate parameters are selected or surface crowning is performed, good meshing quality is ensured, except when the gear ratio $N_{2} / N_{1}<3$.

\section{Declaration}

\section{Acknowledgements}

The authors sincerely thanks to Professor Zong-De Fang of Northwestern Polytechnical University for his critical discussion and reading during manuscript preparation.

\section{Funding}

Supported by National Natural Science Foundation of China (Grant No. 51605378), and Shaanxi Provincial Natural Science Foundation of China (Grant Nos. 2020JM-521)

\section{Availability of data and materials}

The datasets supporting the conclusions of this article are included within the article.

\section{Authors' contributions}

The author' contributions are as follows: Xian-Long Peng was in charge of the whole content of the manuscript.

\section{Competing interests}

The authors declare no competing financial interests.

\section{Consent for publication}

Not applicable

\section{Ethics approval and consent to participate}

Not applicable

\section{References}

[1] Litvin FL, Fuentes A (2004) Gear geometry and applied theory, 2nd ed., Cambridge University Press, New York, Chap. 18.

[2] Litvin FL, Egelja A, Tan J et al (2000) Handbook on face gear drives with a spur involute pinion. University of Illinois at Chicago, Chicago, Illinois, Technical Report No. ARL-CR-447.

[3] Li ZMQ, Zhu RP (2007) Process Method of face gear drive with spur involute pinion with the shaping machine. Journal of Chongqing University 30(7): 55-58 (in Chinese).

[4] GUO H, Fuentes A (2020) Compensation of errors of alignment caused by shaft deflections in face gear drives generated by shaper cutters. Mech Mach. Theory 144: 46-65.

[5] Tang JY, Yin F, Chen XM (2013) The principle of profile modified face gear grinding based on disk wheel. Mechanism and Machine Theory 70: 1-15.

[6] Wang YZ, Chu XM, Huang YZ etal (2019) Surface residual stress distribution for face gear under grinding with a long-radius disk wheel. International Journal of Mechanical Sciences 159: 260-266.

[7] Wang YZ, LanZ, Hou LW et al (2017) An efficient honing method for face gear with tooth profile modification. The International Journal of Advanced Manufacturing Technology 90: 1155-1163.

[8] Zhou YS, Wang SH, Wang LM et al (2019) CNC milling of face gears with a novel geometric analysis. Mechanism and Machine. Theory 139: 46-65.

[9] Zhou RC, Zhao N, Li W (2019) A grinding method of face gear mating with a conical spur involute pinion. Mechanism and Machine Theory 141: 226-244.

[10] Litvin FL, Fuentes A, Zanzi C (2002) Face-gear drive with spur involute pinion:geometry, generation by a worm, stress analysis. Computer Methods in Applied Mechanics and Engineering 191: 2785-2813.

[11] Stadtfeld, HJ (2010) Coniface face gear cutting and grinding, Gear Solutions 10(1): 38-47.

[12] Stadtfeld, HJ (2012) Method and tool for manufacturing face gear. The Gleason Works, Rochester, NY, US Patent No. US2012/0099939 A1.

[13] Peng XL, Niu QY, Guo W et al (2018) A new method of motion rule synthesis for face gear manufacturing by plane-cutter. ASME Journal of Mechanical Design 140: 023302.

[14] Yang XY, Tang JY (2014) Research on manufacturing method of CNC plunge milling for spur face gear. Journal of Materials Processing Technology 214: 3013-3019.

[15] Yang XY, Tang JY (2016) Research on manufacturing method of planing for spur face-gear with 4-axis CNC planer. The International Journal of Advanced Manufacturing Technology 82: 847-858.

[16] Kubo A, Ueda A (2018) Gear Geometry as a Function of the Production Method. Mechanisms and Machine Science 51: 27-44.

[17] WU DR (1959) Lecture notes on differential geometry, 4th ed., People's Education Press, Beijing, Chap. 5 (in Chinese).

[18] Shih YP, Shi, DC (2012) A flank correction methodology for a five-axis CNC gear profile grinding machine. Mechanism and Machine Theory 47: 31-45.

[19] Gonzalez PI, Fuentes A, Hayasaka K. (2010) Analytical determination of basic machine-tool settings for generation of spiral 
bevel gears from blank data. ASME Journal of Mechanical Design 132(10): 101002.

[20] Shih YP, Sun ZH, Wu FC (2018) A disk tool cutting method for bevel gear manufacture on a five-axis machine. The International Journal of Advanced Manufacturing Technology 94: 855-865.

[21] Cao XM, Fang ZD, Xu H et al (2008) Design of pinion mchine tool-settings for spiral bevel gears by controlling contact path and transmission errors. Chinese Journal of Aeronautics 21(2): 179-186.

[22] Akimov VV, Lagutin SA, Volkov AE (2007) New approach to the local synthesis of spiral bevel gears. ASME Paper No. DETC2007-34024.

[23] Artoni A., Gabiccini M, Guiggiani M (2008) Nonlinear identification of machine settings for flank form modifications in hypoid gears. ASME Journal of Mechanical Design 130(11): 112602.

[24] Zanzi C, Pedrero JI (2005) Application of modified geometry of face gear drive. Computer Methods in Applied Mechanics and Engineering 194(27-29): 3047-3066.

[25] Peng XL, Zhang L, Fang ZD (2016) Manufacturing process for a face gear drive with local bearing contact and controllable unloaded meshing performance based on ease-off surface modification. ASME Journal of Mechanical Design 138: 043302.

[26] Litvin FL, Fuentes A, Howkins M (2001) Design, generation and TCA of new type of asymmetric face gear drive with modified geometry. Computer Methods in Applied Mechanics and Engineering 190: 5837-5865.

[27] Litvin FL, Fuentes A, Hayasaka K (2006) Design, manufacture, stress analysis, and experimental tests of low-noise high endurance spiral bevel gears. Mechanism and Machine. Theory 41(1): 83-118.

\section{Biographical notes}

Xian-Long Peng, born in 1982, is currently an associate professor at $X i$ ' an University of Science and Technology, China. He received his $\mathrm{PhD}$ degree from Northwestern Polytechnical University, China, in 2013. His research interests include gear transmission design and manufacturing.

Tel: +86-181-92270760; E-mail: pxljsh@xust.edu.cn 
Figures

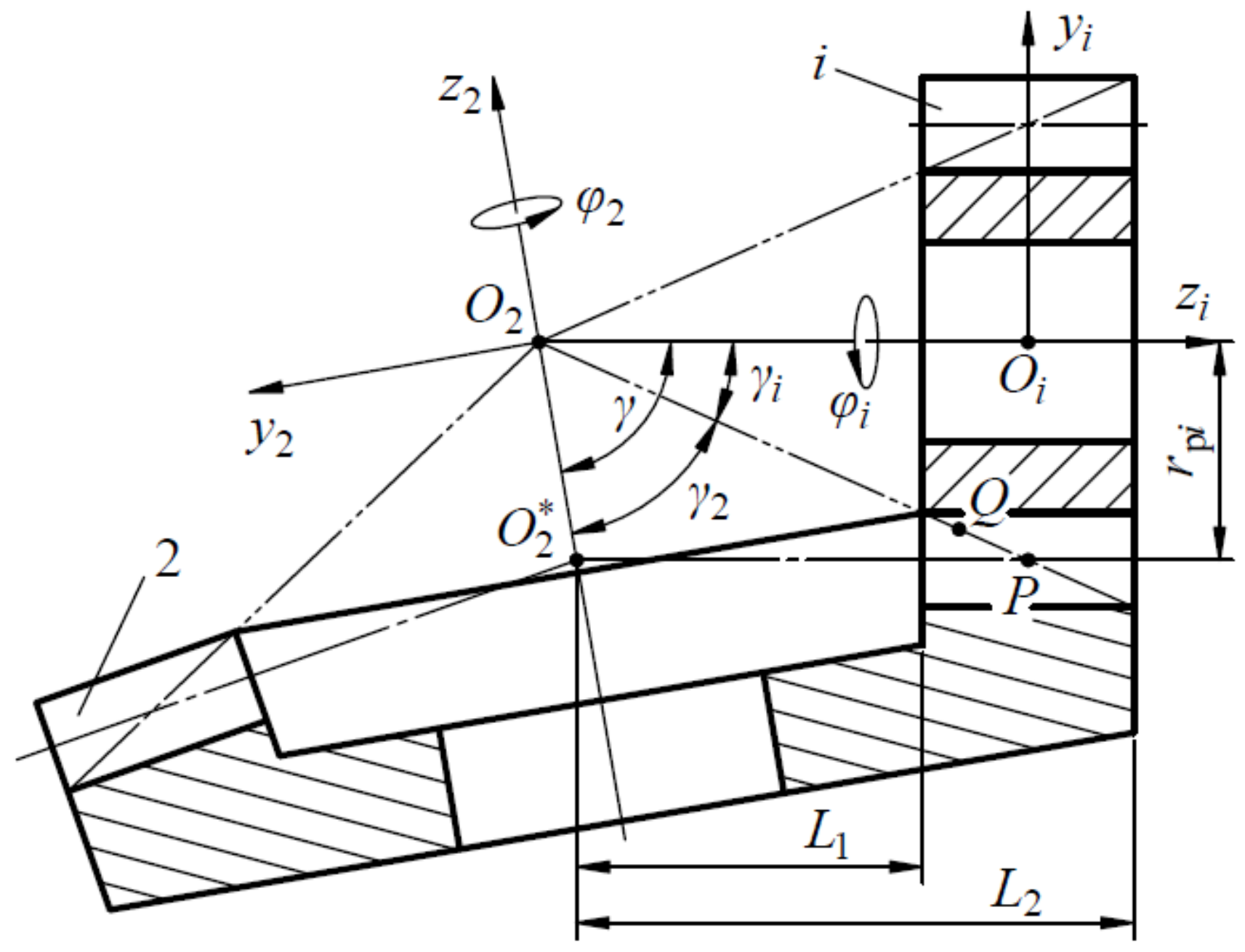

Figure 1

Face gear meshed with a pinion $(\mathrm{i}=1)$ or a shaper $(\mathrm{i}=\mathrm{s})$ 


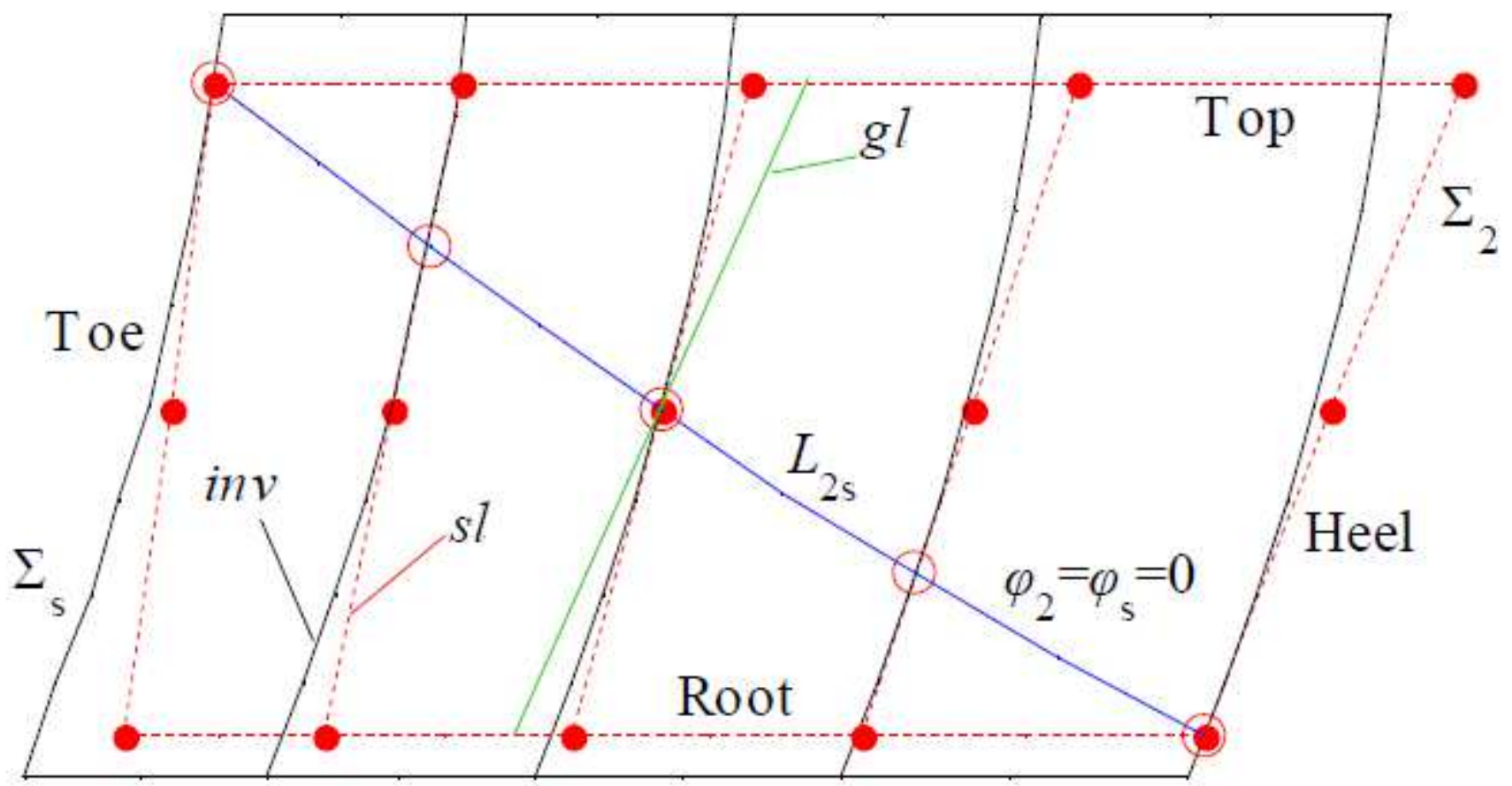

Figure 2

A Special Contact Line in Surfaces $\Sigma$ s and $\Sigma 2$ 


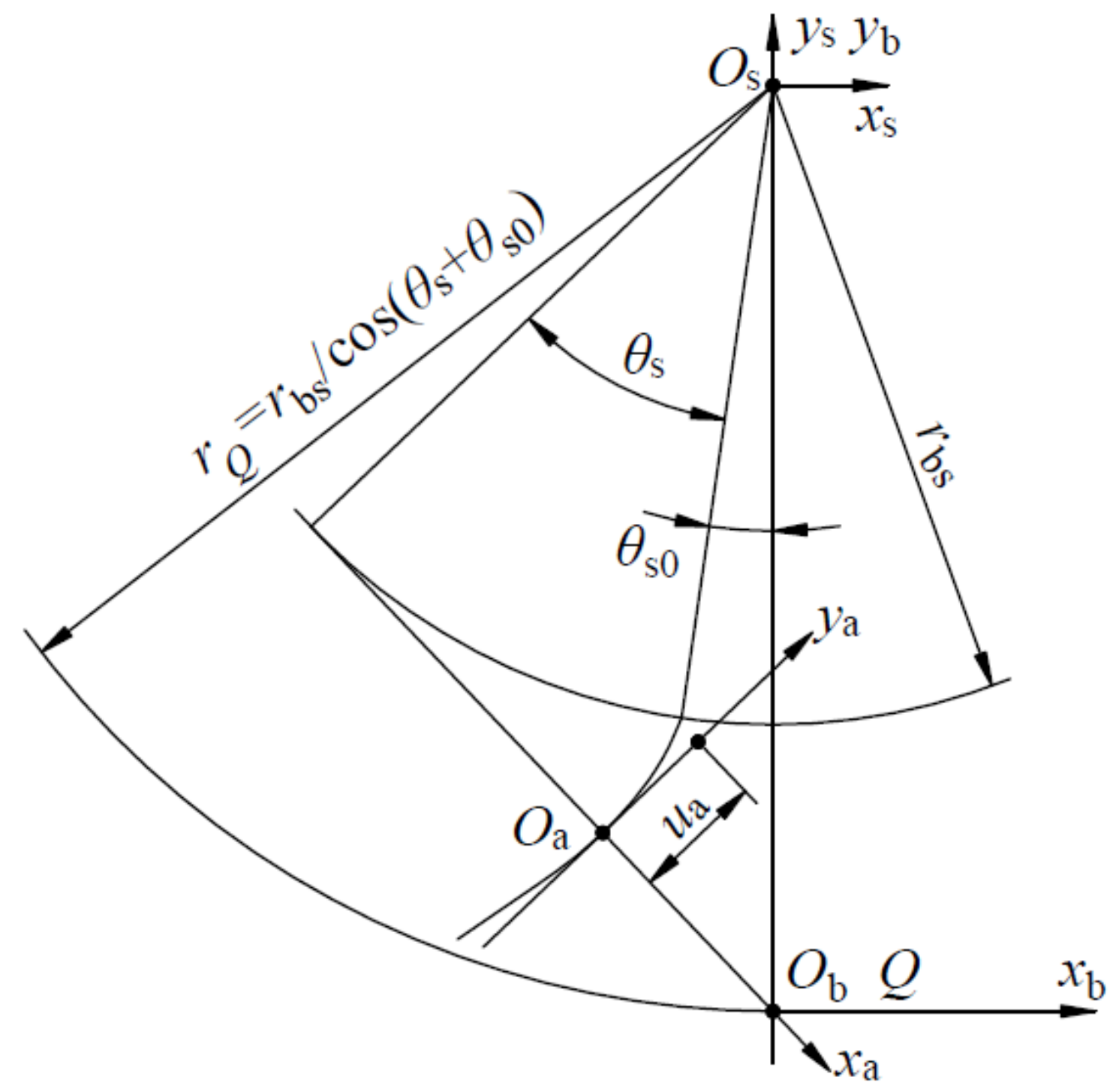

Figure 3

Involute and tangent line at any point 


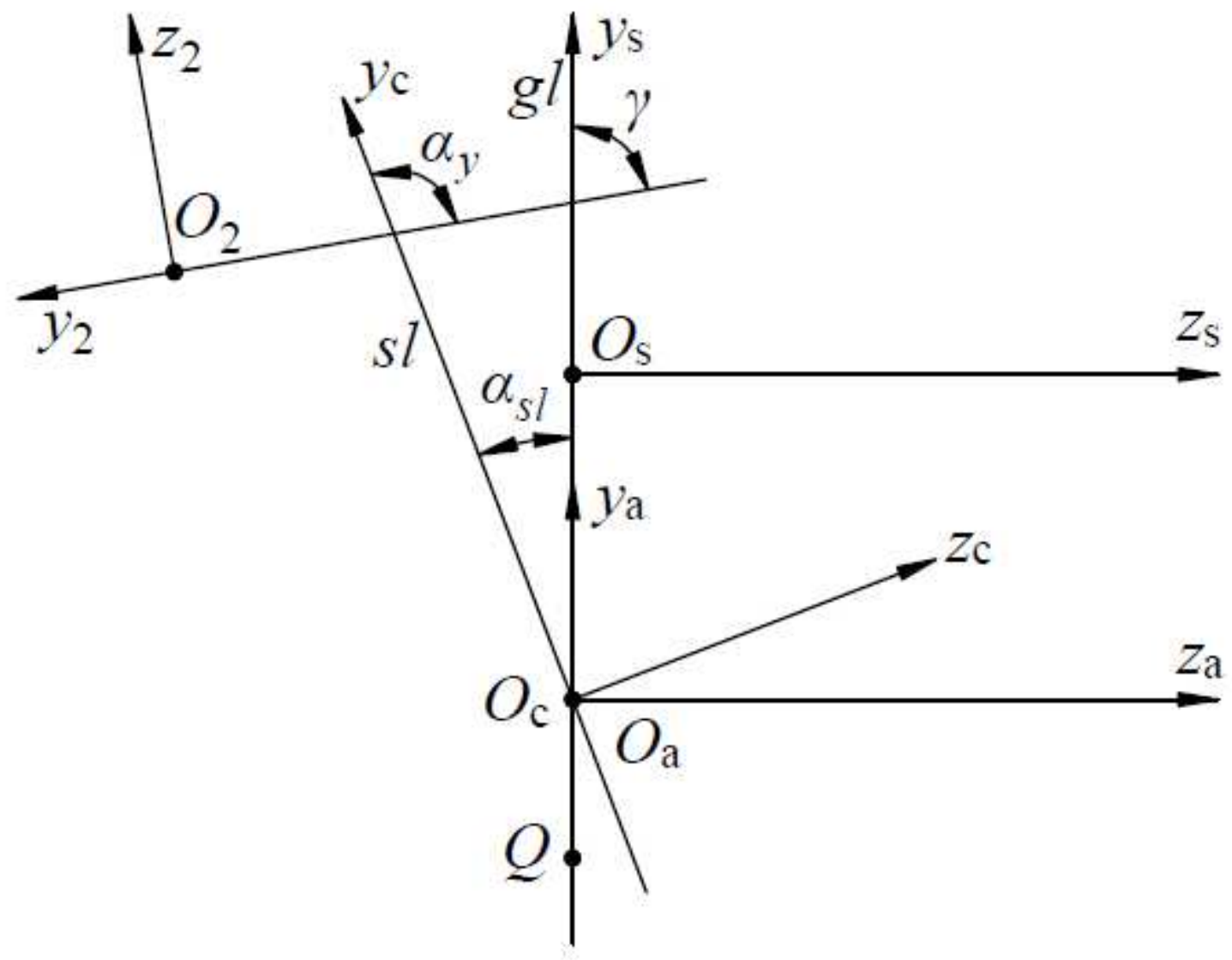

Figure 4

Sketch of the differential angle between lines sl and gl 

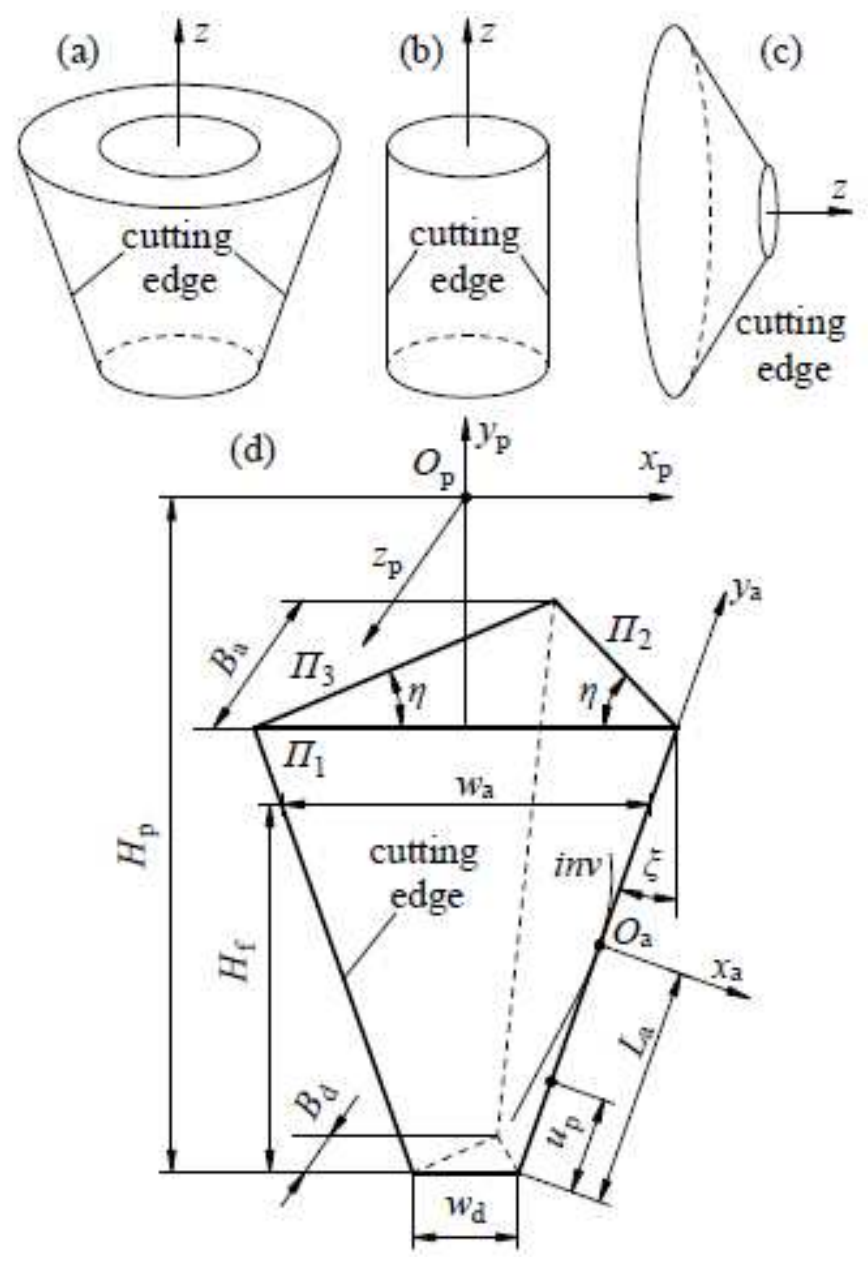

Figure 5

Suitable cutters for new tooth surface generation: (a) finger-shaped cutter, (b) cylindrical milling cutter, (c) cone disk milling cutter/grinding wheel, and (d) planing cutter 


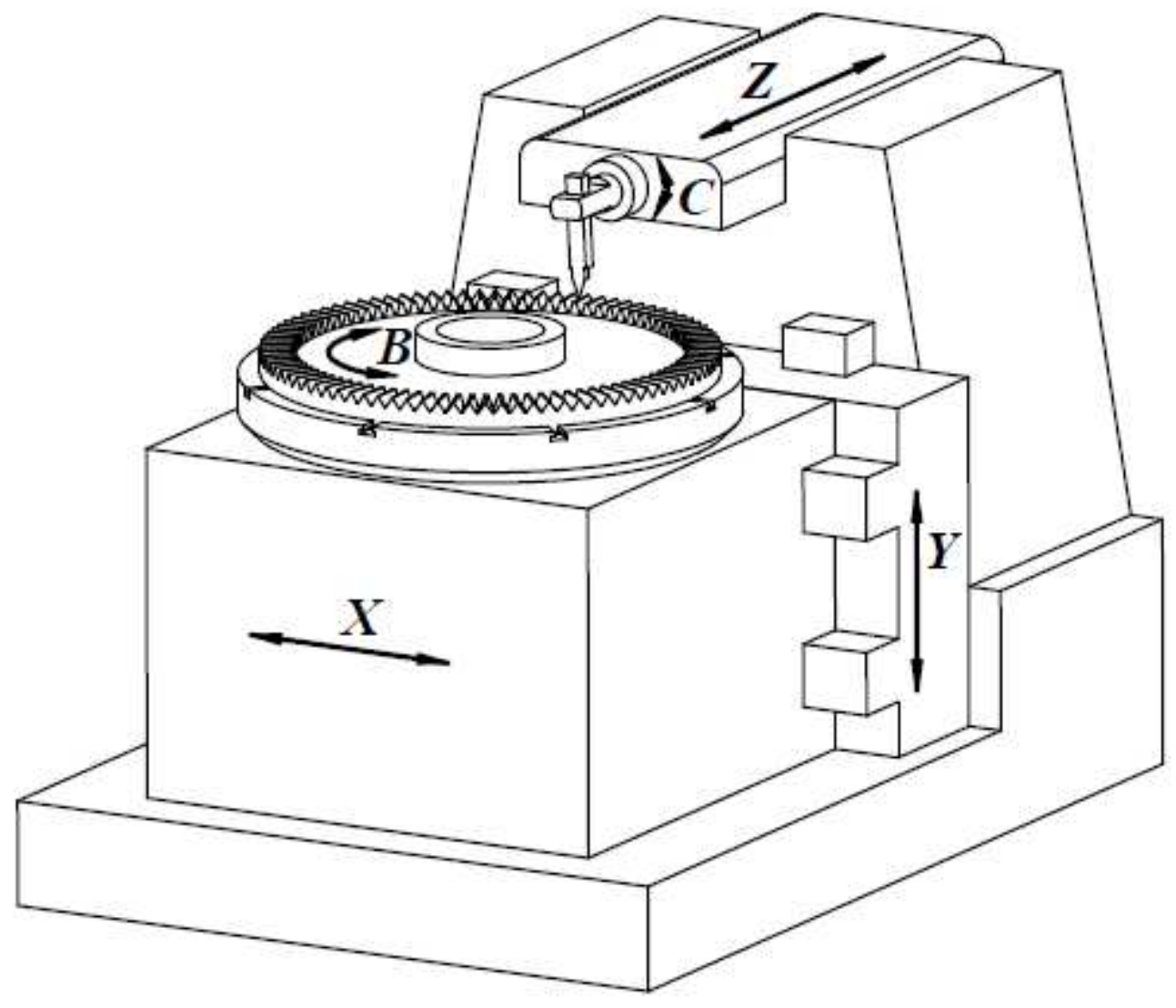

Figure 6

Five-axis NC planer used for face gear generation

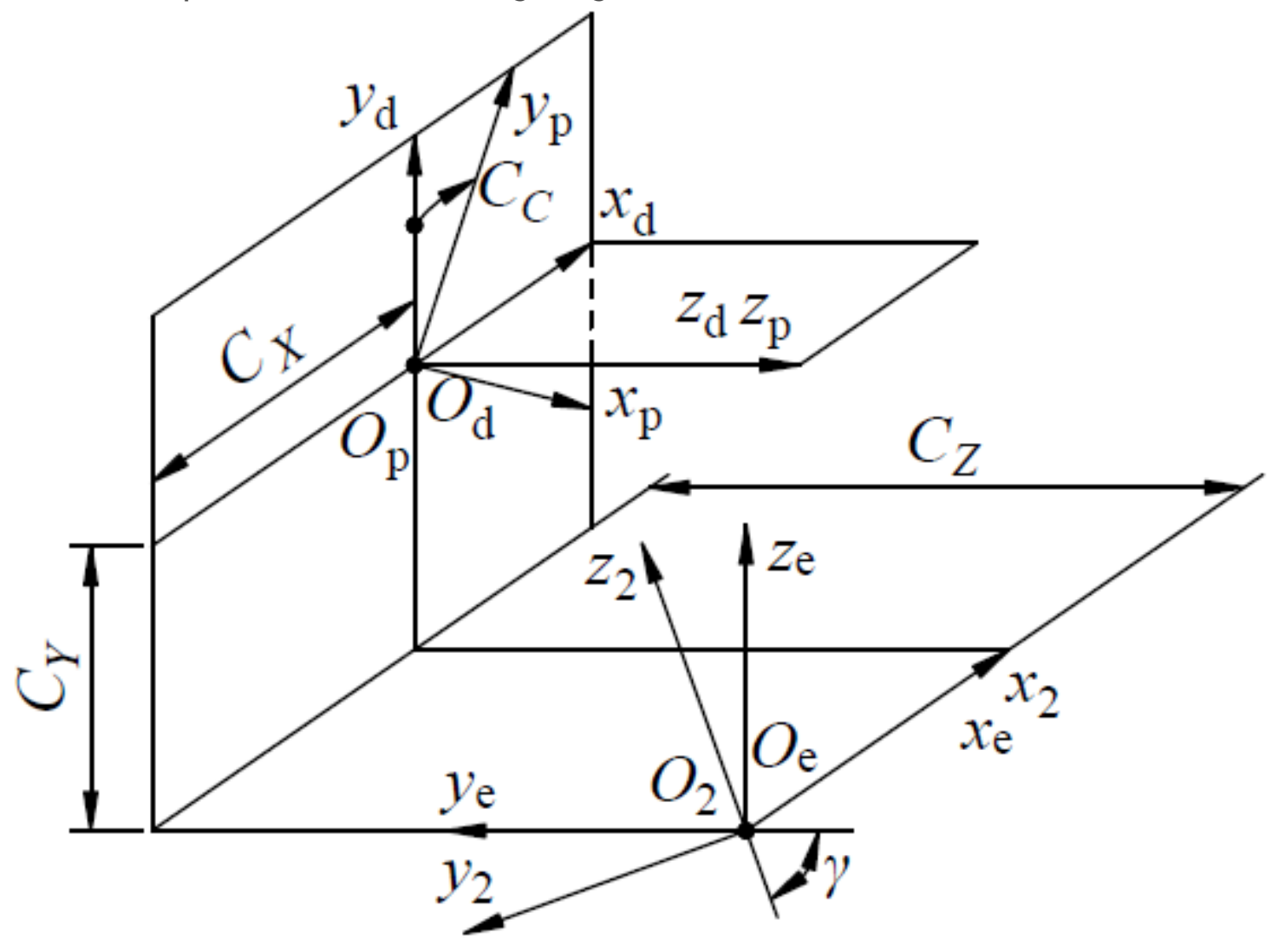


Figure 7

Coordinate systems for face gear generation
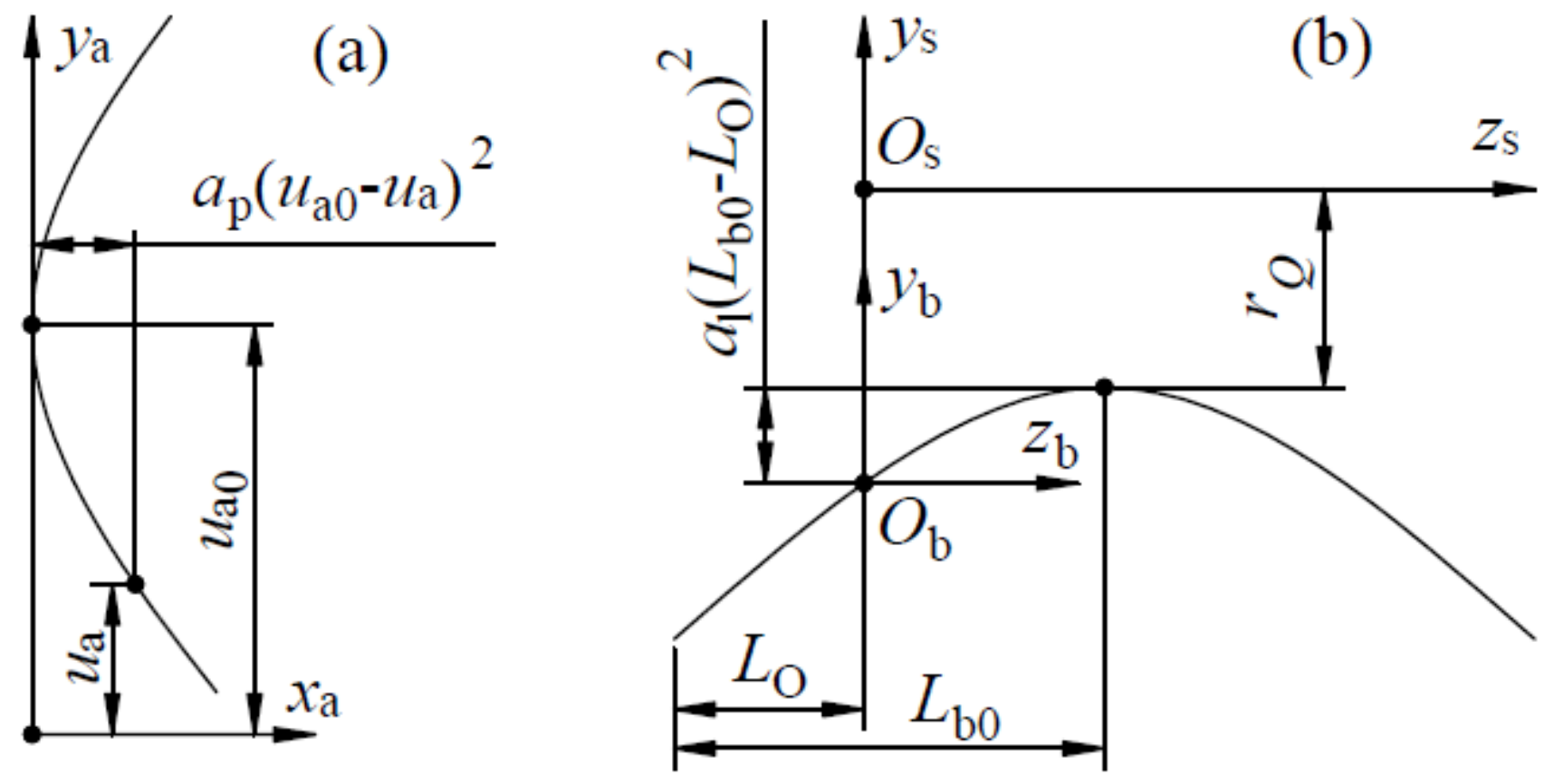

Figure 8

Double crowning for the newly defined tooth surface 


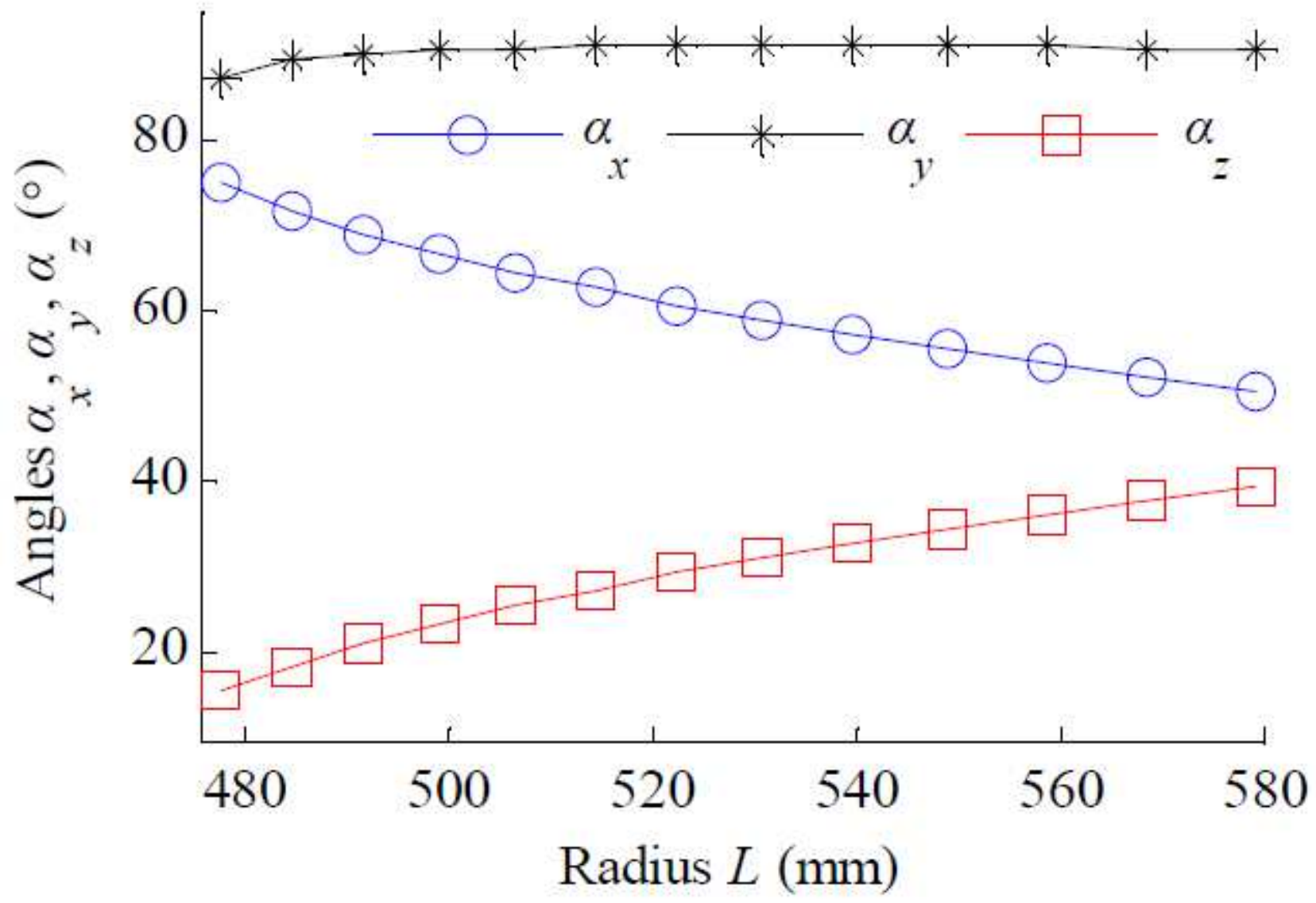

Figure 9

Direction angles of the straight profile line

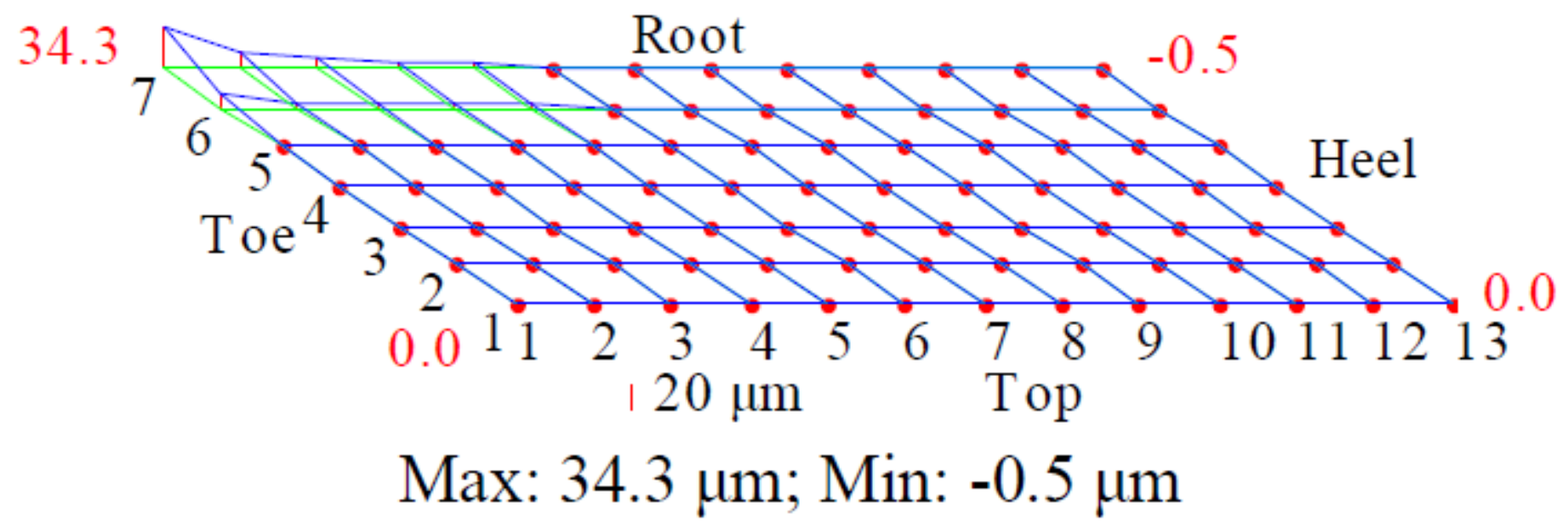

Figure 10

Deviation in the straight profile line 


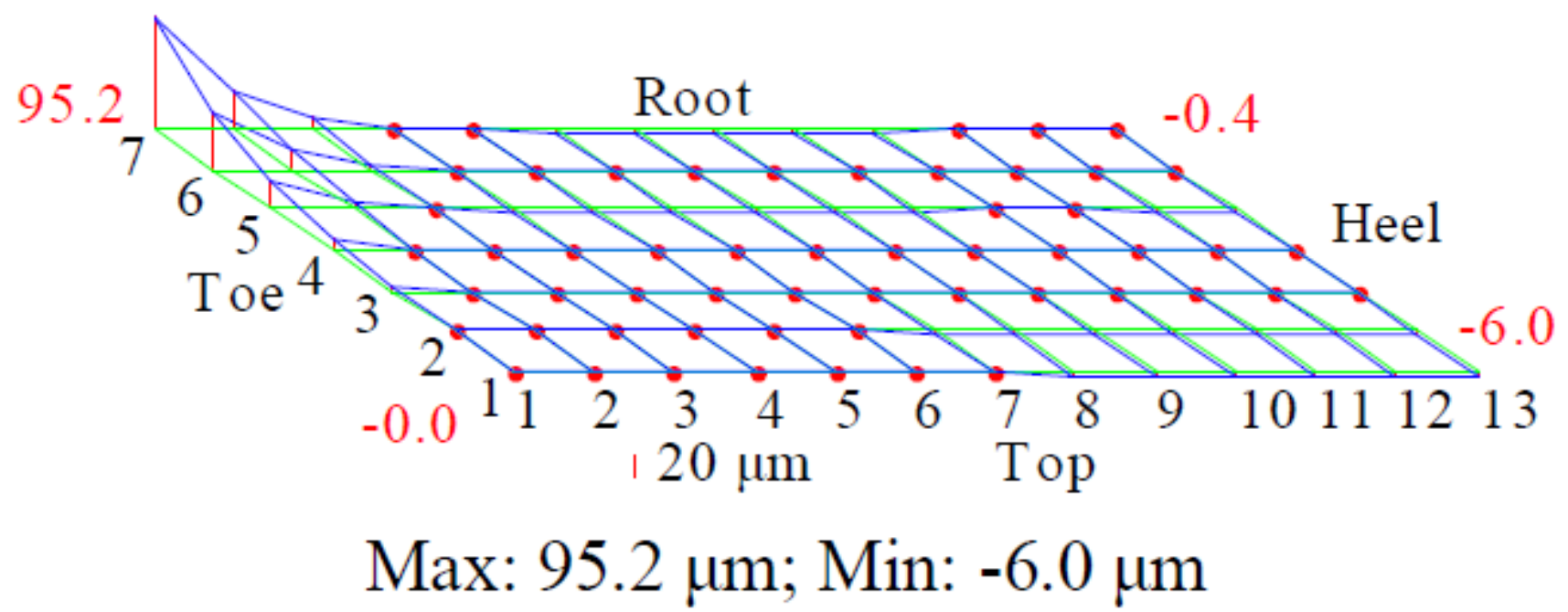

Figure 11

Deviation in the developable ruled surface

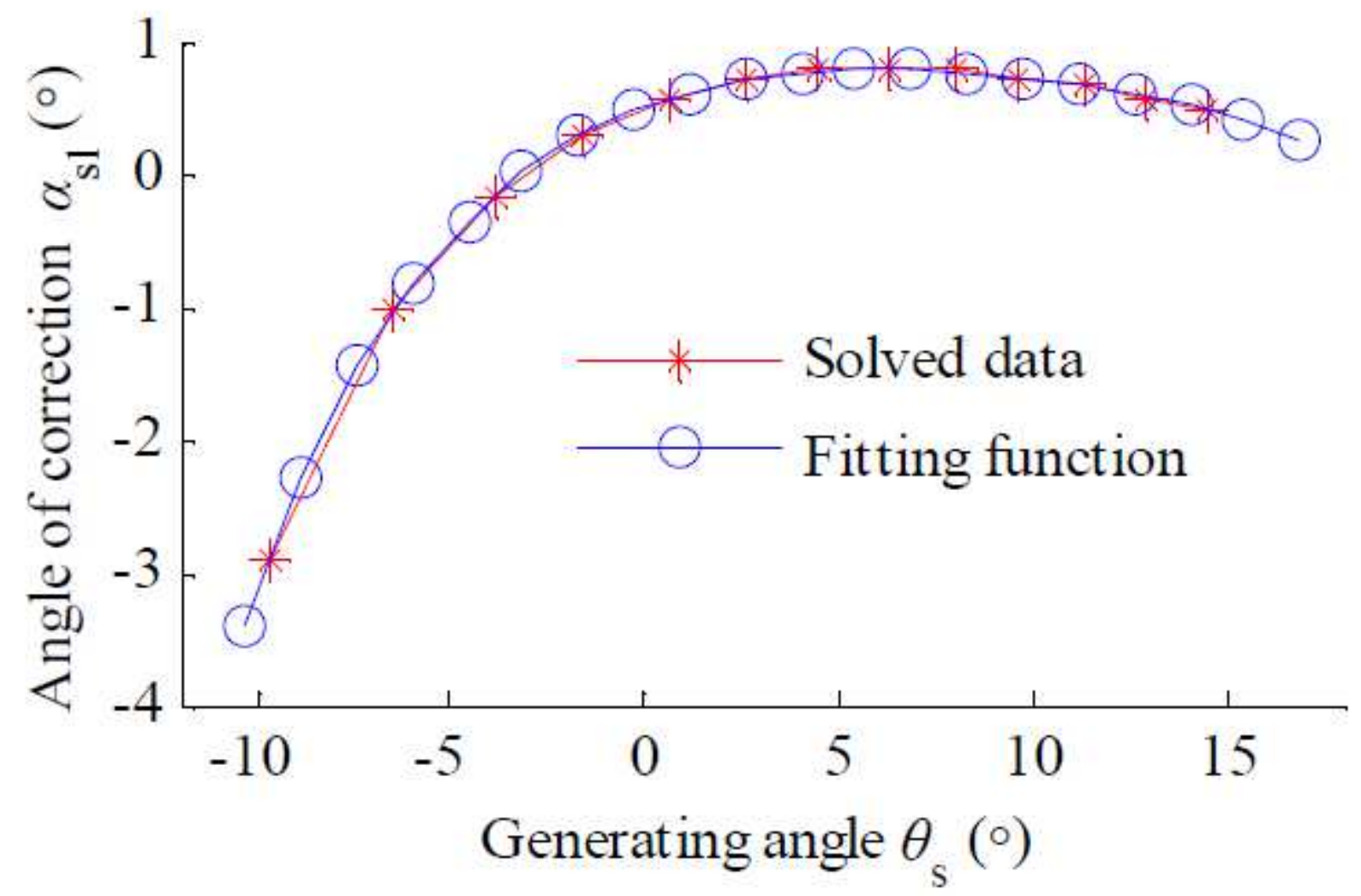

Figure 12

Differential angle of the straight profile line 
9.0

\section{Root}

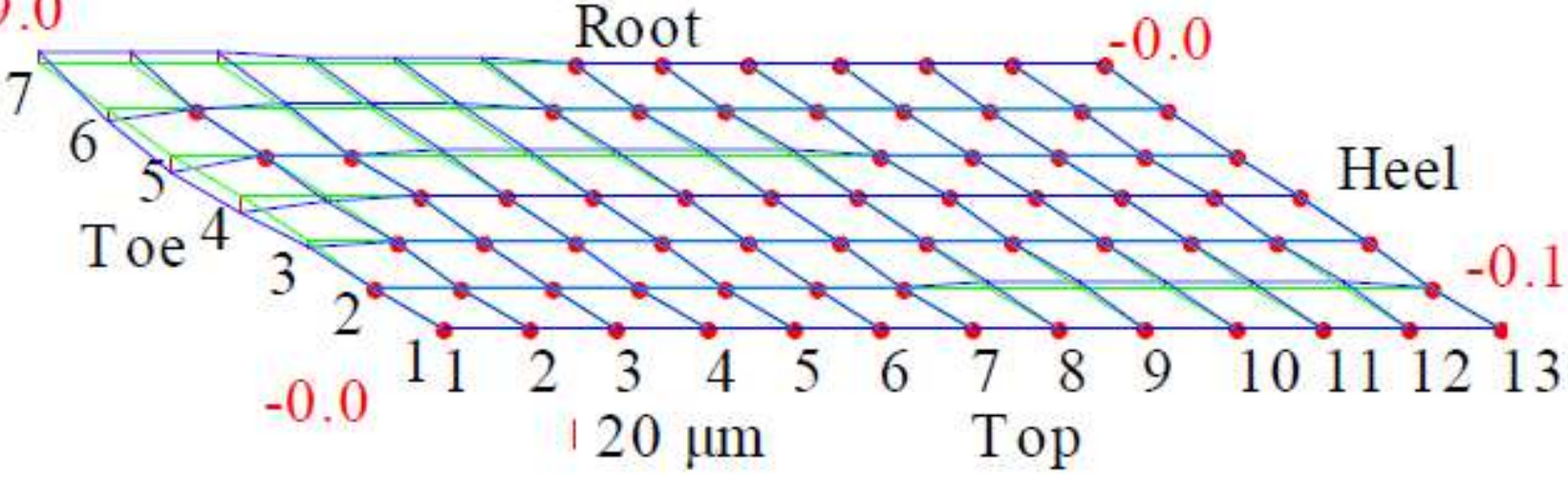

Max: $9.0 \mu \mathrm{m}$; Min: $-14.6 \mu \mathrm{m}$

\section{Figure 13}

Deviation in surface $\Sigma \mathrm{N} 2$ after correction

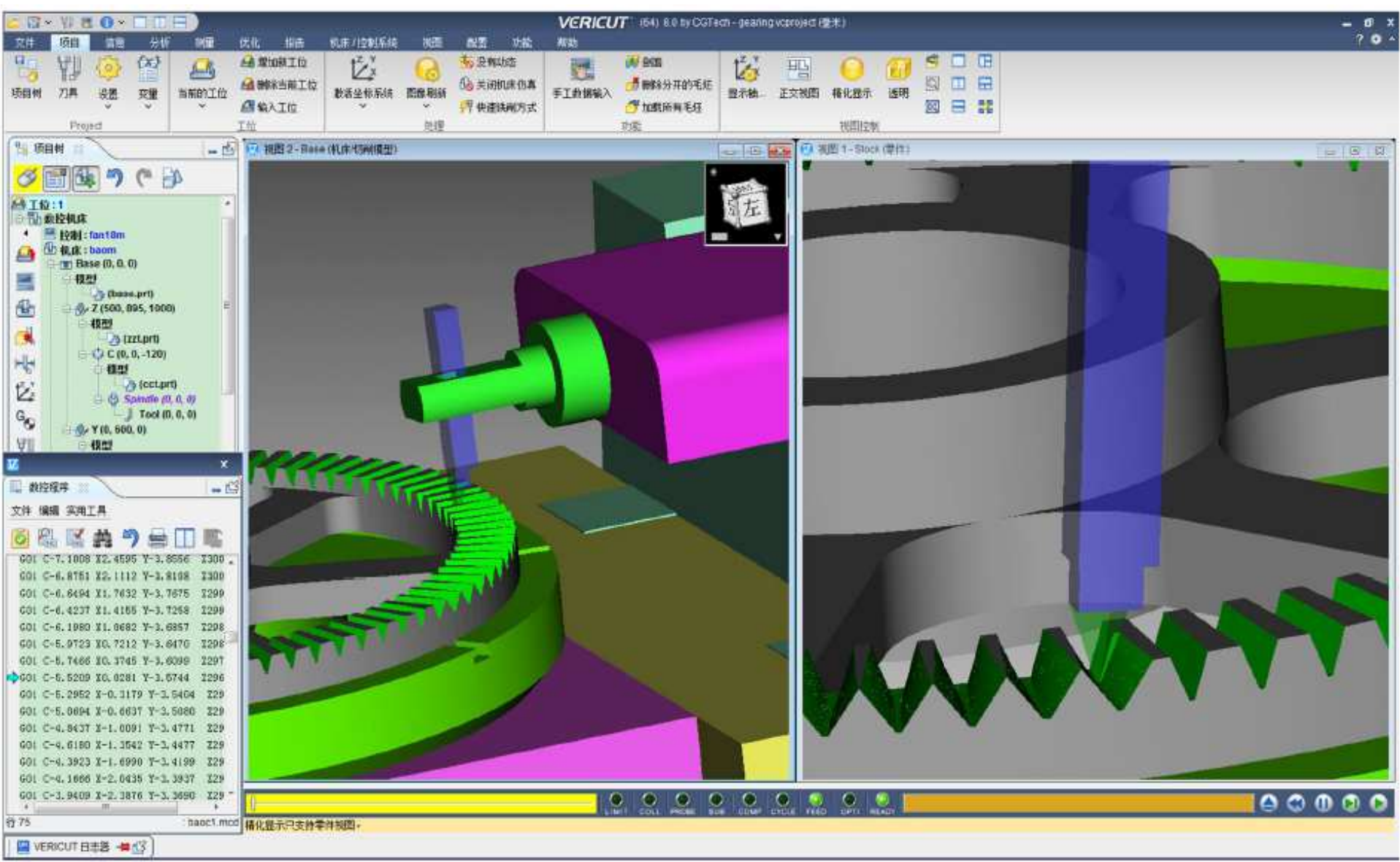

Figure 14

Cutting simulation for the face gear using VERICUT (its video is on the web:

https://v.qq.com/x/page/z3133gsj38v.html) 


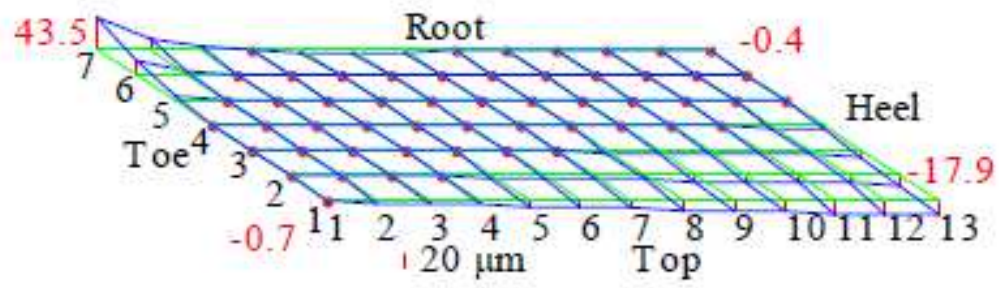

Max: $43.5 \mu \mathrm{m}$; Min: $-18.0 \mu \mathrm{m}$

(a) Principle deviation

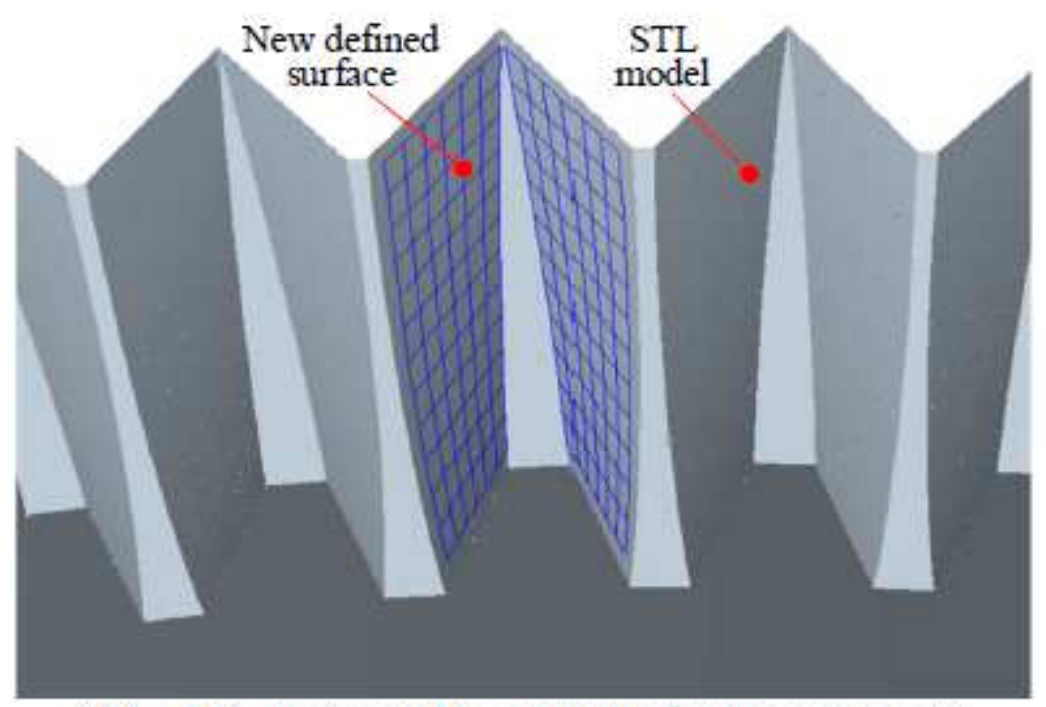

(b) STL model and topography for measurements

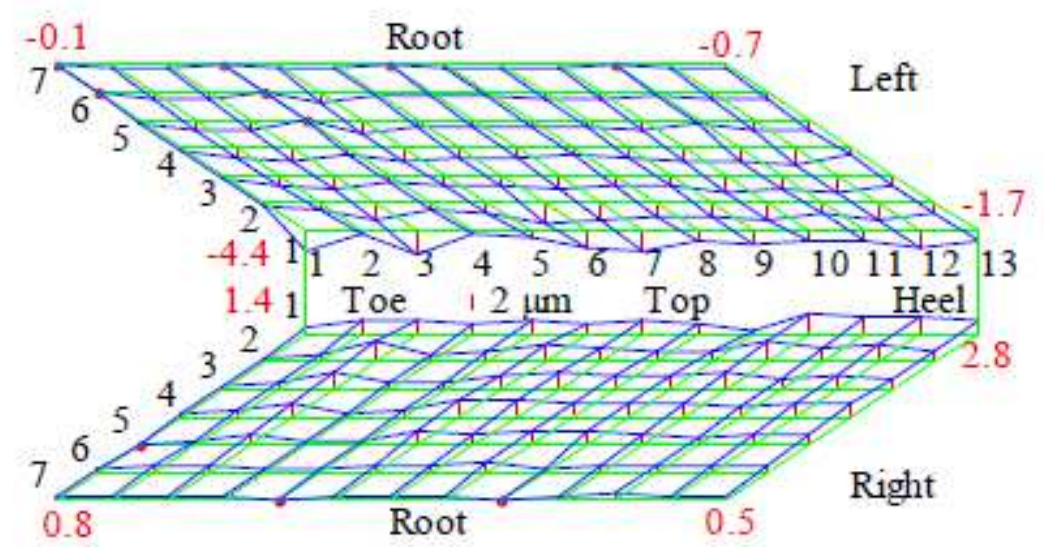

Left Max: $-0.0 \mu \mathrm{m}$; Left Min: $-5.4 \mu \mathrm{m}$; Right Max: $4.5 \mu \mathrm{m}$; and Right Min: $0.0 \mu \mathrm{m}$

(c) Topographic deviations in the machined STL model

Figure 15

Results of the simulated tooth surface 

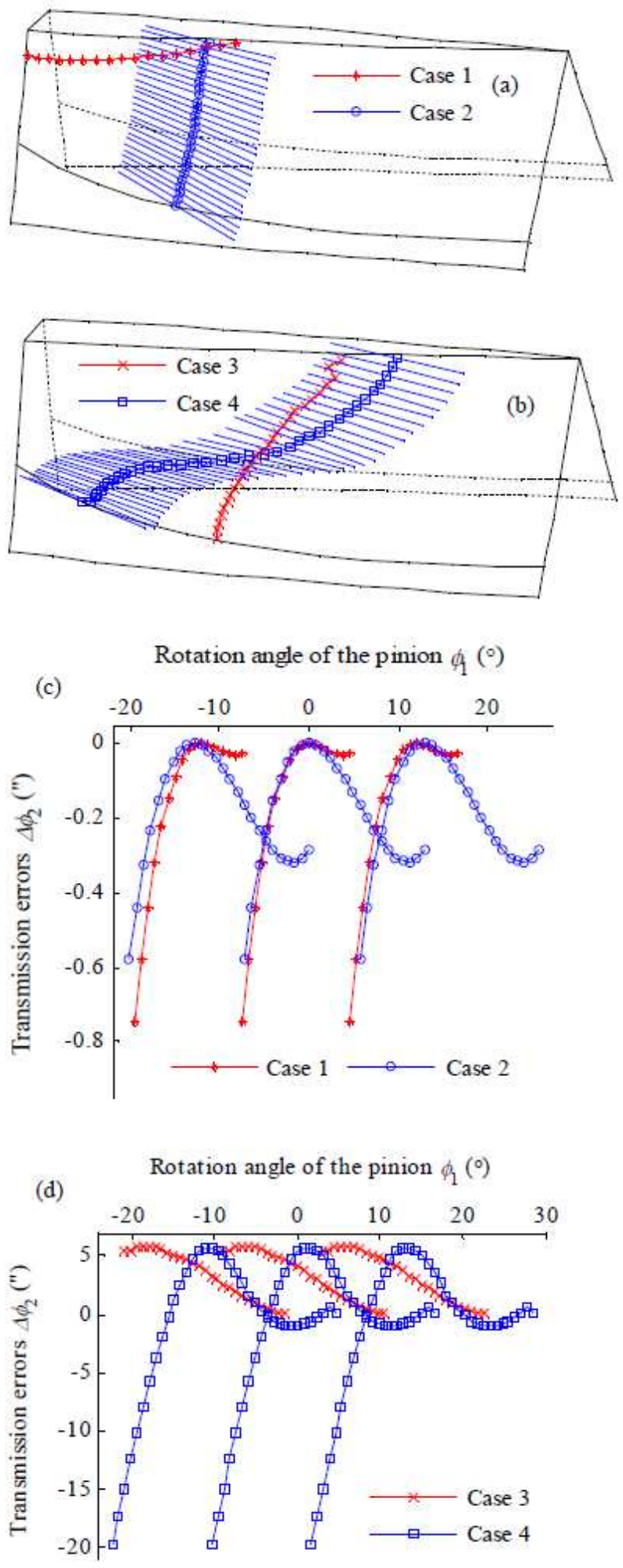

\section{Figure 16}

Results of meshing and contact simulation 